\title{
Experimental characterization of the COndensation PArticle counting System for high altitude aircraft-borne application
}

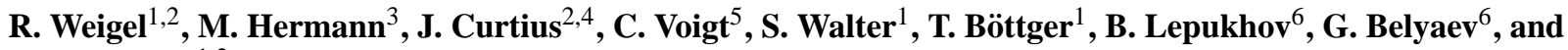 \\ S. Borrmann ${ }^{1,2}$ \\ ${ }^{1}$ Max Planck Institute for Chemistry, Particle Chemistry Department, Mainz, Germany \\ ${ }^{2}$ Institute for Atmospheric Physics, Johannes Gutenberg-University, Mainz, Germany \\ ${ }^{3}$ Leibniz Institute for Tropospheric Research, Leipzig, Germany \\ ${ }^{4}$ Institute for Atmosphere and Environment, Johann Wolfgang Goethe University, Frankfurt, Germany \\ ${ }^{5}$ German Aerospace Center (DLR), Institute for Atmospheric Physics, Oberpfaffenhofen, Germany \\ ${ }^{6}$ Myasishchev Design Bureau, Moscow, Russia
}

Received: 17 September 2008 - Published in Atmos. Meas. Tech. Discuss.: 28 November 2008

Revised: 7 April 2009 - Accepted: 27 May 2009 - Published: 16 June 2009

\begin{abstract}
A characterization of the ultra-fine aerosol particle counter COPAS (COndensation PArticle counting System) for operation on board the Russian high altitude research aircraft M-55 Geophysika is presented. The COPAS instrument consists of an aerosol inlet and two dual-channel continuous flow Condensation Particle Counters (CPCs) operated with the chlorofluorocarbon FC-43. It operates at pressures between 400 and $50 \mathrm{hPa}$ for aerosol detection in the particle diameter $\left(d_{p}\right)$ range from $6 \mathrm{~nm}$ up to $1 \mu \mathrm{m}$. The aerosol inlet, designed for the M-55, is characterized with respect to aspiration, transmission, and transport losses. The experimental characterization of counting efficiencies of three CPCs yields $d_{p 50}$ (50\% detection particle diameter) of $6 \mathrm{~nm}, 11 \mathrm{~nm}$, and $15 \mathrm{~nm}$ at temperature differences $(\Delta T)$ between saturator and condenser of $17^{\circ} \mathrm{C}, 30^{\circ} \mathrm{C}$, and $33^{\circ} \mathrm{C}$, respectively. Non-volatile particles are quantified with a fourth CPC, with $d_{p 50}=11 \mathrm{~nm}$. It includes an aerosol heating line $\left(250^{\circ} \mathrm{C}\right)$ to evaporate $\mathrm{H}_{2} \mathrm{SO}_{4}-\mathrm{H}_{2} \mathrm{O}$ particles of $11 \mathrm{~nm}<d_{p}<200 \mathrm{~nm}$ at pressures between 70 and $300 \mathrm{hPa}$. An instrumental in-flight inter-comparison of the different COPAS CPCs yields correlation coefficients of 0.996 and 0.985 . The particle emission index for the M-55 in the range of $1.4-8.4 \times 10^{16} \mathrm{~kg}^{-1}$ fuel burned has been estimated based on measurements of the Geophysika's own exhaust.
\end{abstract}

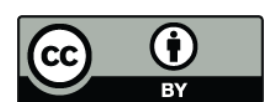

Correspondence to: R. Weigel (weigelr@uni-mainz.de)

\section{Introduction}

In-situ measurements of fine aerosol particles $\left(d_{p}<1000 \mathrm{~nm}\right)$ from high-altitude aircraft are essential for studies concerning the atmospheric radiative budget, stratospheric chemistry, aerosol processes of the tropical tropopause region, polar stratospheric cloud (PSC) microphysics, as well as for comparisons with ground based or satellite borne remote sensors. Stratospheric aerosol particles scatter solar radiation and these particles exert a significant influence on the stratosphere's radiation budget and on the Earth's planetary albedo, especially after volcanic injections (Hamill et al., 1997, and references therein). Another important objective of investigations is to determine the quantitative and qualitative contribution of aerosol particles to chemical transformation processes in the stratosphere. The particles provide the essential surfaces for important chemical reactions (Prather and Rodriguez, 1988; Peter, 1997). For example, stratospheric aerosol particles play a significant role in heterogeneous processes forming reactive chemical species which are known to participate in ozone depletion (Wennberg, et al., 1994; Murphy and Ravishankara, 1994; Carslaw et al., 1994; Peter, 1997; Borrmann et al., 1997; Voigt et al., 2000, 2003).

A major fraction of the stratospheric aerosol is assumed to consist of $\sim 75$-weight-percent solution of sulfuric acid and water $\left(\mathrm{H}_{2} \mathrm{SO}_{4} / \mathrm{H}_{2} \mathrm{O}\right)$ (Rosen, 1971; Arnold et al., 1998; Murphy et al., 2007). Besides $\mathrm{H}_{2} \mathrm{SO}_{4}$ and $\mathrm{H}_{2} \mathrm{O}$, also refractory compounds are found in stratospheric particles, such as soot (or other refractory carbonaceous material), meteoric material, and volcanic ashes (Turco et al., 1982; Murphy et al.,

Published by Copernicus Publications on behalf of the European Geosciences Union. 
1998, 2007; Cziczo, 2001; Curtius et al., 2005). Particularly the refractory material might have a significant impact on various processes such as PSC activation in the polar winter vortex (Peter, 1997; Murphy et al., 1998, 2007; Curtius et al., 2005; Voigt et al., 2005).

Since 2002, the University of Mainz and the Max Planck Institute for Chemistry in Mainz (Germany) developed and operated two separate units of aircraft-borne dual-channel condensation particle counters (CPCs), the COndensation PArticle counting Systems (COPAS), on board the high altitude research aircraft M-55 Geophysika (http://emz-m.ru/ M55-e.htm). This study provides a detailed description and comprehensive characterization of the CPCs counting efficiency and other critical instrument parameters at the relevant atmospheric conditions. The characterization also includes coincidence studies (miscounting two or more individual particles as only one in the detector), as the coincidence effect is strongly dependent on the individual CPC design. Also subject of the experiments was to characterize the vaporizing properties of the aerosol pre-heating device. Furthermore, a limited number of flight measurements are used for a reliability study, to demonstrate the instrumental performance and the limits of the COPAS operation, particularly with respect to the flight altitude. Finally, two crossings of the M-55's own exhaust at altitudes of $16-18 \mathrm{~km}$ were used to provide an order of magnitude estimate of the particle emission index of the M-55.

\section{Details of the instrumental design}

The COPAS instrument was originally based on a CPC design developed by the University of Denver (USA) for measurements on board the NASA ER-2 (Wilson et al., 1983a, b). The terminus of two dual-channel CPCs is used in this study to refer to the two independent units, each containing two coupled CPCs. For technical reason the two CPCs of a unit are thermally coupled by a common heat sink and both CPCs of a unit sample from a common aerosol inlet, but there is an independent aerosol inlet for each unit.

The information from the four CPC channels is used to obtain a) the total number concentration of particles with diameters $>11 \mathrm{~nm}, \mathrm{~b}$ ) the number concentration of ultra-fine particles (with diameters $6 \mathrm{~nm}<d_{p}<15 \mathrm{~nm}$ ) by operating two CPCs with different temperatures of the saturator and the condenser, and c) the concentration of stratospheric aerosol particles with temperature-stable cores $>11 \mathrm{~nm}$ diameter by using an aerosol heating line upstream of one COPAS channel. The particle fraction which remains after passing the heated $\left(250^{\circ} \mathrm{C}\right)$ aerosol line is specified to be non-volatile with respect to $250^{\circ} \mathrm{C}$ in the following.

The two almost identical units of the dual-channel COPAS are positioned at different locations on board of the M-55, one in an instrument bay that is part of the main body of the aircraft and one in a bay under the left wing. The independent measurements of the disjunct units also provide possibilities to cross-check and verify the data from the different channels and from the often redundant information additional reliability of the data is assured.

The COPAS CPCs are thermo-diffusion-type counters (Rosen et al., 1974; Sinclair and Hoopes, 1975; Wilson et al., 1983a, b; Stolzenburg and McMurry, 1991) which are usually operated with butanol $\left(\mathrm{C}_{4} \mathrm{H}_{9} \mathrm{OH}\right)$ or FluorInert FC$43\left(\left(\mathrm{C}_{4} \mathrm{~F}_{9}\right)_{3} \mathrm{~N}\right)$, a commercially available fluorocarbon, as working fluids. The process of thermo-diffusion in the condenser volume leads to supersaturation followed by particle growth up to sizes at which the particles are sufficiently large to be optically detected. To allow for continuous sampling with a frequency $\sim 1 \mathrm{~Hz}$ and precise measurements at particle concentrations $<100 \mathrm{~cm}^{-3}$, this working principle is used for COPAS instead of expansion-type CPCs (e.g. Kürten et al., 2005).

The $d_{p 50}$ characterizing a CPC is defined as the particle diameter for which

$d_{p 50}=\frac{n_{\text {det }}\left(d_{p}\right)}{n_{\text {real }}\left(d_{p}\right)}=0.5$,

here $n_{\text {det }}\left(d_{p}\right)$ is the detected number concentration of monodisperse particles of size $d_{p}$ and $n_{\text {real }}\left(d_{p}\right)$ is the real number concentration. Commercially available CPCs usually have a $d_{p 50}$ between 2.5 and $20 \mathrm{~nm}$. CPCs used on research aircraft in the past typically had $d_{p 50}$ of 3-10 nm (Wilson et al., 1983b; Dreiling and Jaenicke, 1988; Brock et al., 1995; Hermann and Wiedensohler, 2001; Minikin et al., 2003). Reviews on the general designs and the development of different types of CPCs are available from McMurry (2000) and Spurny (2000).

The COPAS operation principle with actively controlled volumetric sample air flow is shown in Fig. 1. Each dual channel COPAS is equipped with one aerosol inlet. The incoming airflow is split into two equal CPC flows. In each CPC channel, the incoming airflow is split again into two subflows. The major part of the flow $(\sim 90 \%)$ is cleaned from aerosol particles by a total aerosol filter. Subsequently, the cleaned air becomes saturated with the vapor of the working liquid in the saturator chamber in which a constant temperature is maintained (COPAS-I: both channels $32^{\circ} \mathrm{C}$; COPASII: $24^{\circ} \mathrm{C}$ and $40^{\circ} \mathrm{C}$ for channel one and two, respectively). The remaining fraction of the incoming air $(\sim 10 \%)$ is the sample flow which carries the aerosol particles. This flow passes a capillary with a nozzle-shaped tip. At the exit of this capillary the two subflows - the sample flow and the particlefree, saturated air - are merged again. The saturated airflow now acts as a sheath flow which focuses the sample flow into the condenser and thus helps to avoid particle losses due to turbulences, diffusion, and thermophoretic effects (Wilson et al., 1983b). In the condenser the total air flow is cooled to temperatures of $2^{\circ} \mathrm{C}$ (COPAS-I) and $7^{\circ} \mathrm{C}$ (COPAS-II) leading to a supersaturation of the working fluid vapor. This supersaturation drives the growth of the aerosol particles to sizes 
that are detectable by a suitable photo-optical sensor which is comparable to the detector of the CPC TSI model 3760 (TSI Incorporated, 2002).

The total flow rates of the COPAS units are monitored by use of differential pressure sensors at the sample flow capillary and the common exhaust line for both CPCs (cf. Fig. 1). The automated flow regulation (with $10 \mathrm{~Hz}$ integration loop frequency) of each COPAS instrument controls the air pump frequency (and therefore the flow rate of both CPCs of one COPAS) according to settings which can be described by the linear relation $y=a \cdot x+b$ of total standard volume flow rate (y) in $\mathrm{cm}^{3} \min ^{-1}$ as a function of ambient pressure $(x)$ in hPa with the parameters for COPAS-I: $a=2.09, b=40.60$ and COPAS-II: $a=2.23, b=36.56$. The automated flow regulation generally works within an accuracy range of $\pm 15 \%$. However, if ascent and descent rates of the airborne platform significantly exceed $10 \mathrm{~m} \mathrm{~s}^{-1}$ the differential pressure measurement shows disturbances, probably caused by turbulent flow conditions within the flow measurement volume. Irregular flow measurements have direct influence on the air flow regulation and therefore on the instrumental performance (cf. Sect. 8).

The differential pressure measurement requires a calibration related to the volume flow rate, which is dependent on the pressure conditions. A bubble flow meter was used to calibrate the flow rate derived from the changes of measured differential pressure of each COPAS channel in the pressure range of $1000-50 \mathrm{hPa}$.

\subsection{Adaptation to airborne operation}

The COPAS CPCs - intended for aircraft-based operation up to $21 \mathrm{~km}$ - are mounted within the aircraft's hull but exposed to a wide range of ambient conditions such as pressures as low as $50 \mathrm{hPa}$, temperature conditions from $+50^{\circ} \mathrm{C}$ (on the runway) down to $-80^{\circ} \mathrm{C}$ at the tropical tropospause, and changes between these extremes within $\sim 30 \mathrm{~min}$. Important properties of the COPAS instruments, compared to commercially available CPCs, are:

- The saturator of each COPAS channel is equipped with an active heating device. Thus the saturator temperature is maintained at its set-points within $\pm 0.5^{\circ} \mathrm{C}$ during a complete flight (in the Arctic as well as in tropical regions).

- FluorInert (FC-43) is preferably used as the working liquid instead of butanol. In particular, for CPC applications at high altitudes with pressure conditions below $200 \mathrm{hPa}$ the use of FC-43 is favored due to its better performance. FC-43 has a three times smaller diffusion coefficient than butanol. Thus at ambient pressure below $200 \mathrm{hPa}$ butanol condensation on the particles while passing the saturator is not sufficiently efficient anymore. Detailed discussion concerning the pressure dependent performance of butanol compared

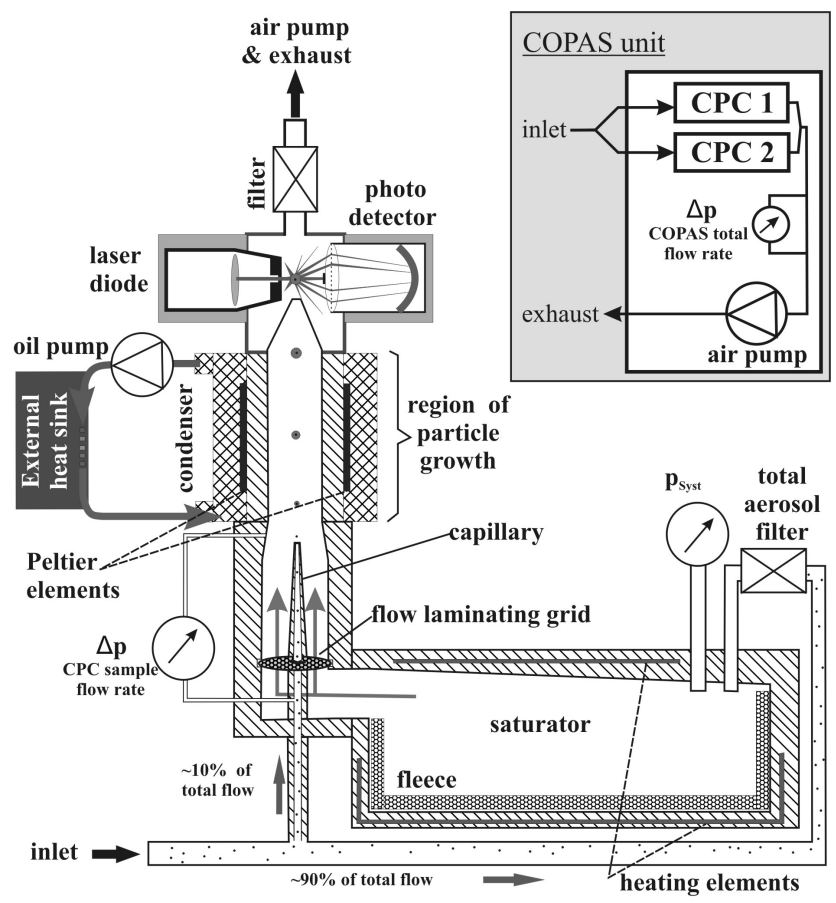

Fig. 1. Flow scheme of a COPAS CPC channel. Two such counter channels are implemented in one COPAS instrument unit. Two COPAS units (with two CPC channels each) are mounted at different locations on the M-55 Geophysika.

to FC-43 as CPC working fluid are provided by Hermann et al. (2005). FC-43 has also been used on the NASA ER-2 (J. C. Wilson, personal communication).

- Peltier elements are used for the cooling of the condenser, with their warm sides being cooled by a low viscosity silicone oil circuit. A custom-designed oil circuit is running through the shaft of the inlet probe, where the oil is efficiently cooled (cf. Sect. 2.3). Minimum oil temperatures of $<-37^{\circ} \mathrm{C}$ are reached during flight. The Peltier elements are adjusting the temperature to a set point with an accuracy of $\pm 0.5^{\circ} \mathrm{C}$.

- The air flow through the COPAS unit is regulated as a function of ambient pressure by a frequencycontrolled air pump (Brey G12/02-8) with an accuracy of $\pm 0.151 \mathrm{~min}^{-1}$ at standard temperature and pressure (STP).

- The data acquisition and control of COPAS is achieved by custom-made electronics. Data are typically recorded with $1 \mathrm{~Hz}$ frequency on flash memory (PCMCIA card).

\subsection{The inlet probe}

The two COPAS inlet probes consist of three parts, the base plate, the shaft, and the inlet head. Figure 2 shows a 


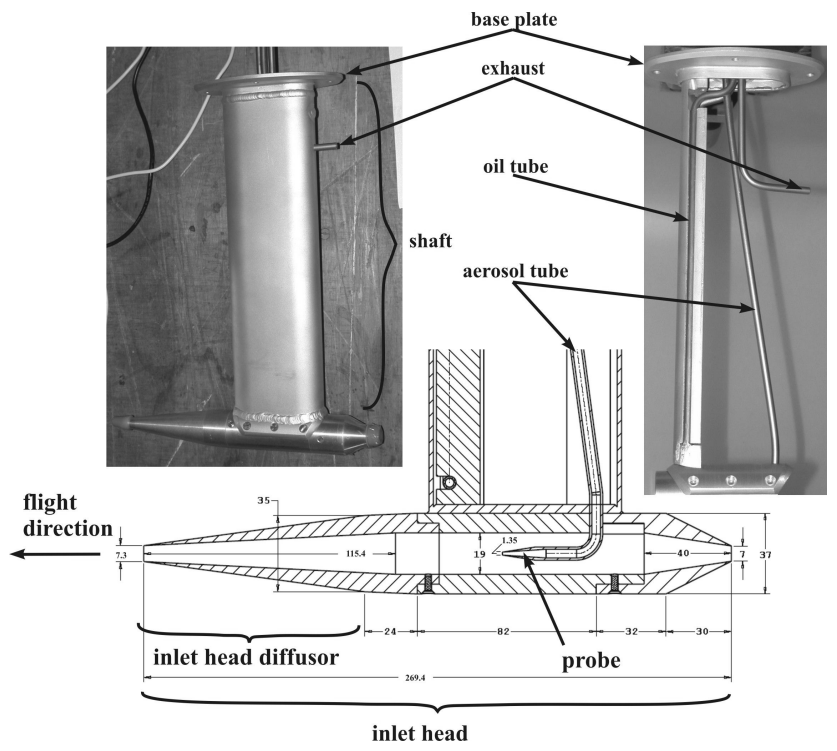

Fig. 2. The COPAS aerosol inlet for measurements on-board the M-55. The inlet head consists of a diffuser-type entrance with sharp inlet lips. Inside the head, the so-called probe is implemented, also equipped with a diffuser-type inlet with sharp lips. The inlet shaft includes the aerosol intake and exhaust lines as well as the heat exchanger pipes for the silicone oil coolant circuit (dimensions in millimeter).

schematic drawing of the different parts and photographic images of the device.

For the COPAS measurements on board the M-55 diffusertype, non-shrouded inlets with sharp-edged inlet lips were used (2.9 $9^{\circ}$ diffuser half-angle), a custom-made reproduction of the inlet used on board the NASA ER-2 which is described in detail by Wilson et al. (1992). Each of the two inlets is mounted with a negative angle related to the longitudinal axis of the M-55 respecting the aircraft's positive mean angle of attack of about $7-8^{\circ}$ at flight altitudes above $5 \mathrm{~km}$. Thus, for cruising flight operations the aerosol inlet is mounted isoaxial within accuracy of $\pm 1^{\circ}$. Below $5 \mathrm{~km}$ altitude, particularly during take-off and landing phase, the inlet is misaligned from isoaxial condition by up to $\pm 6^{\circ}$.

The shaft length of $300 \mathrm{~mm}$ insures an aerosol probing outside the boundary layer of the M-55 (Myasishchev Design Bureau, 2002). Beside the aerosol sampling line and the exhaust tube the shaft contains the oil cooling circuit.

\subsection{The condenser cooling oil circuit}

Figure 3 shows the measured oil temperature during a flight in tropical regions (12 February 2005, TROCCINOX mission, Araçatuba, Brazil) as an example for extreme ambient temperature conditions influencing the COPAS measurement performance. The ambient temperature as well as the oil temperature is shown as a function of flight altitude. From the temperature profiles it becomes obvious that high ambient

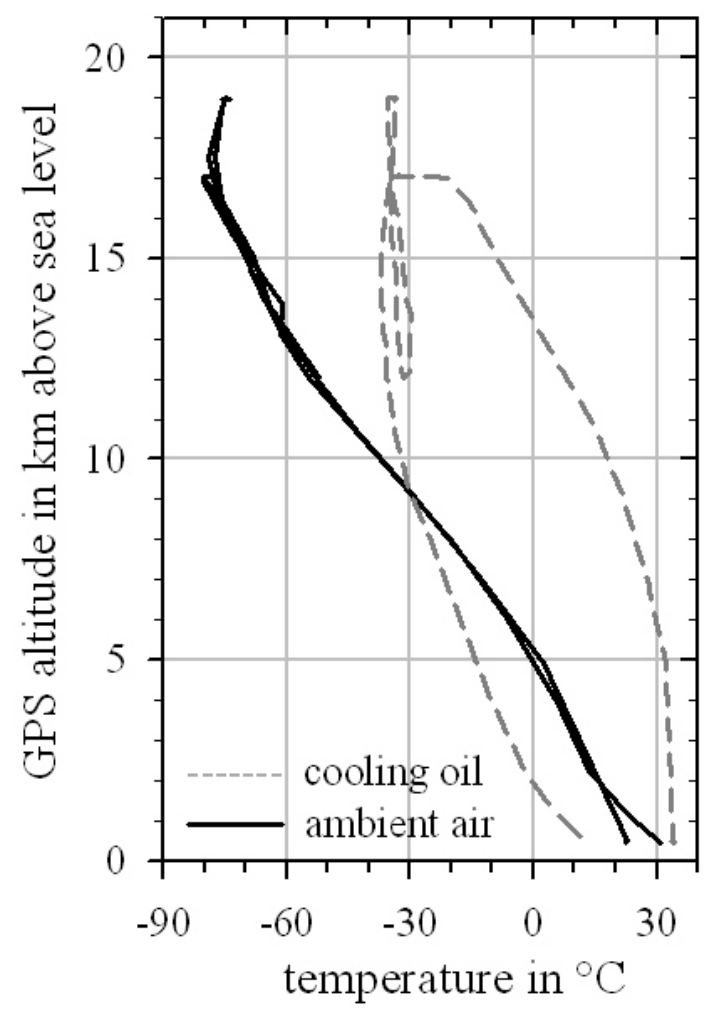

Fig. 3. Vertical ambient temperature profile and the recorded temperature of the cooling oil circuit during a flight (12 February 2005, longitude: $41^{\circ}-51^{\circ}$ west; latitude: $17^{\circ}-21^{\circ}$ south) in tropical regions (State of São Paolo, Brazil).

temperatures on the ground caused oil temperatures of up to $33^{\circ} \mathrm{C}$. During ascent, the oil temperature remained above $10^{\circ} \mathrm{C}$ until reaching flight altitudes of $12 \mathrm{~km}$. At $12 \mathrm{~km}$ altitude an oil temperatures of $10^{\circ} \mathrm{C}$ is reached for which the condenser temperature is in the range of given settings. For oil temperatures above $10^{\circ} \mathrm{C}$ the condenser temperatures are out of range and according measurement data have to be discarded from further analysis (cf. Sect. 8).

\section{Determination of COPAS sampling characteristics}

The performance of an aerosol inlet system can be described by the inlet particle sampling efficiency (aspiration and transmission) and the transport efficiency through the sampling lines to the instruments (Baron and Willeke, 2001). The aspiration is related to the fraction of the ambient particles which enter the aerosol inlet, while the transmission efficiency denotes the particle fraction that passes through the inlet. The transport efficiency is determined by the particle losses in the sampling line between the inlet and the instrument and describes the fraction of particles that are able to reach the detection chamber. The following three sections describe 
the sampling efficiency of the COPAS aerosol inlet and the aerosol sampling line transport efficiency.

\subsection{Aspiration efficiency of the COPAS aerosol inlet}

For representative measurements an aerosol probe must sample outside of the aircraft boundary layer and outside of zones of depletion or enhancement for particles caused by the flow distortion around the aircraft hull. These conditions are met for both COPAS inlet positions on board the M-55. Deviations from the isoaxial alignment of the COPAS aerosol inlet above $5 \mathrm{~km}$ flight altitude in the range of $\pm 1.5^{\circ}$ can be neglected for sub-micrometer particle sampling. Particle losses due to anisoaxial sampling become significant for particles and droplets $>1 \mu \mathrm{m}$ only (Baron and Willke, 2001).

To evaluate the isokinetic property of the COPAS aerosol inlet 2-D CFD modeling studies with FLUENT were performed by Walter (2004). For the calculations compressible gas properties were assumed considering the maximum flight speed of the M-55 of up to Mach 0.7. For both the inlet head diffuser and the probe diffuser the calculations yield the ratios $R$ of air flow velocities between outside and inside the respective inlet entrance. The results of $R_{i h}=1.2$ for the COPAS inlet head and $R_{p}=1.7$ for the probe sampling indicate sub-isokinetic sampling conditions for both entrances.

For calculation of the aspiration efficiency the equations from Hangal and Willeke (1990) are used for ambient pressure of $50 \mathrm{hPa}$, considering that anisokinetic effects have the largest impact on particle losses at lowest pressure conditions. Calculations were made related to the $R$ of the inlet head and the probe. The sub-isokinetic sampling conditions become significant for particle sizes well above $d_{p}=500 \mathrm{~nm}$. However, as the particle number concentration in the upper troposphere and lower stratosphere (UT/LS) is strongly dominated by the sub-micrometer particles of $d_{p}<500 \mathrm{~nm}$ (Thomas et al., 2002; Deshler et al., 2003) the results indicate that at UT/LS conditions the obtained aspiration efficiency of the inlet has negligible impact on the measurement with COPAS.

\subsection{Transmission efficiency}

Hermann et al. (2001) provide results of wind tunnel experiments with an aircraft-borne aerosol inlet. They showed that in the COPAS relevant particle size range the transmission is independent from the Reynolds-number and that the transmission efficiency of their inlet decreased for particles larger than $200 \mathrm{~nm}$, reaching zero at about $3 \mu \mathrm{m}$. Without having performed such wind tunnel experiments we assume that the findings of Hermann et al. (2001) can be transferred to our inlet as it represents a very similar non-shrouded diffusertype inlet head with a sharp-edged inlet entrance. Hermann et al. (2001) obtained transmission efficiencies above $75 \%$ for submicron particles. As the sampling inside the COPAS inlet is realized as forward facing probe in contrast to the backward facing probe in Hermann et al. (2001) the transmission efficiency of the COPAS inlet should be even higher. Considering the small number concentration of particles with $d_{p}>1 \mu \mathrm{m}$ in the UT/LS (Thomas et al., 2002; Deshler et al., 2003) the transmission of the COPAS aerosol inlet can be estimated to be about 1 for $d_{p}<500 \mathrm{~nm}$ and better than 0.75 for the sub-micron particle size range of $500 \mathrm{~nm}<d_{p}<1 \mu \mathrm{m}$.

\subsection{Transport efficiency}

A general problem arises from the fact that any correction of the measured particle number concentration related to the particle diffusion losses in the sampling lines requires the knowledge of the initial aerosol size distribution. Only for the measurement of the ultra-fine nucleation-mode particles with $6 \mathrm{~nm}<d_{p}<15 \mathrm{~nm}$, an estimated correction is feasible, but this is also the size range which is most sensitive to particle diffusion losses.

For the diffusion loss mechanism, the particle fraction that penetrates the aerosol lines have been calculated using the empirical equations given by Baron and Willeke (2001) and Hinds (1999). The number concentration of ultrafine particles is determined by subtracting the measurements of the two COPAS CPCs with $d_{p 50} \approx 6 \mathrm{~nm}\left(\Rightarrow n_{6}\right)$ and $d_{p 50} \approx$ $15 \mathrm{~nm}\left(\Rightarrow n_{15}\right)$. This yields the number concentration of particles in the size range between 6 and $15 \mathrm{~nm}\left(n_{6-15}\right)$. Calculated mean particle losses $\bar{\Lambda}_{6-15}$ for the particles between 6 and $15 \mathrm{~nm}$ are given in Table 1 . From $\bar{\Lambda}_{6-15}$ a correction factor $\kappa_{L}$ (for pressure conditions $<150 \mathrm{hPa}, 150-300 \mathrm{hPa}$, and $>300 \mathrm{hPa}$ ) was calculated to correct the ultrafine particle number concentration $n_{6-15}$ :

$\kappa_{L}=\frac{100 \%}{100 \%-\bar{\Lambda}_{6-15}}$,

here, $\bar{\Lambda}_{6-15}$ is given in percent.

\section{Determination of COPAS detection and counting characteristics}

For several CPC models, information on their performance at reduced pressures is available in the literature based on experimental as well as theoretical work (Heintzenberg and Ogren, 1985; Dreiling and Jaenicke, 1988; Noone and Hansson, 1990; Zhang and Liu, 1990, 1991; Saros et al., 1996; Cofer et al., 1998; Hermann and Wiedensohler, 2001, and Hermann et al., 2005). A detailed description of both, the instrumental development and the instrument performance of those CPCs at reduced operating pressure, is given by Hermann and Wiedensohler (2001) who also provided a description of a low-pressure calibration setup. This setup allows for generating monodisperse aerosol particles in different materials and for operating at a pressure range from $1000 \mathrm{hPa}$ down to $50 \mathrm{hPa}$. All experimental characterizations presented in this study concerning the pressure dependent 
Table 1. Pressure dependent particle losses (bold characters in \%) inside the aerosol inlet tubes and according mean particle loss $\bar{\Lambda}_{6-15}$ (in $\%$ ) for the particle size range $6 \mathrm{~nm}<d_{p}<15 \mathrm{~nm}$. Resulting correction factor $\kappa_{L}$ (dimensionless) are exclusively used for the ultra-fine size fraction $n_{6-15}$ determined from results of COPAS-II.

\begin{tabular}{cccccccccccc}
\hline \multirow{2}{*}{ pressure in $\mathrm{hPa}$} & \multicolumn{1}{c}{ particle diameter in $\mathrm{nm}$} & \multicolumn{1}{c}{$\bar{\Lambda}_{6-15}$} & \multirow{2}{*}{ resulting $\kappa_{L}$} \\
& 6 & 7 & 8 & 9 & 10 & 11 & 12 & 14 & 15 & & \\
\hline 70 & $\mathbf{3 6}$ & $\mathbf{3 0}$ & $\mathbf{2 6}$ & $\mathbf{2 3}$ & $\mathbf{2 0}$ & $\mathbf{1 8}$ & $\mathbf{1 6}$ & $\mathbf{1 4}$ & $\mathbf{1 3}$ & 21.8 & 1.28 \\
150 & $\mathbf{3 1}$ & $\mathbf{2 6}$ & $\mathbf{2 2}$ & $\mathbf{2 0}$ & $\mathbf{1 7}$ & $\mathbf{1 6}$ & $\mathbf{1 4}$ & $\mathbf{1 2}$ & $\mathbf{1 1}$ & 18.8 & 1.23 \\
300 & $\mathbf{2 6}$ & $\mathbf{2 2}$ & $\mathbf{1 9}$ & $\mathbf{1 7}$ & $\mathbf{1 5}$ & $\mathbf{1 3}$ & $\mathbf{1 2}$ & $\mathbf{1 0}$ & $\mathbf{9}$ & 15.9 & 1.19 \\
400 & $\mathbf{2 2}$ & $\mathbf{1 9}$ & $\mathbf{1 6}$ & $\mathbf{1 4}$ & $\mathbf{1 3}$ & $\mathbf{1 1}$ & $\mathbf{1 0}$ & $\mathbf{8}$ & $\mathbf{7}$ & 13.3 & 1.15 \\
\hline
\end{tabular}

Table 2. Resulting $d_{p 50}$ of each COPAS channel obtained from the experimental CPC characterization studies at two operating pressure conditions with Ag-particles. Additionally, respective $\Delta T$ for each COPAS channel and according factor of supersaturation $f_{S}$ of the working fluid FC-43 is listed.

\begin{tabular}{ccccc}
\hline & \multicolumn{5}{c}{$d_{p 50} \pm \bar{\sigma}_{\eta}$ (in nm) } \\
& \multicolumn{6}{c}{ COPAS-I channel } & COPAS-II channel \\
& 1 & 2 & 1 & 2 \\
\hline $70 \mathrm{hPa}$ & $12.4 \pm 1.8$ & $9.5 \pm 1.1$ & $12.3 \pm 0.6$ & $6.0 \pm 0.3$ \\
$300 \mathrm{hPa}$ & $11.1 \pm 1.0$ & $10.6 \pm 0.7$ & $18.8 \pm 0.9$ & $6.6 \pm 0.2$ \\
$\Delta T$ & \multicolumn{2}{c}{$30^{\circ} \mathrm{C}$} & $17^{\circ} \mathrm{C}$ & $33^{\circ} \mathrm{C}$ \\
$f_{S}$ & \multicolumn{2}{c}{7.5} & 3.2 & 8.4 \\
\hline
\end{tabular}

counting efficiencies of the COPAS CPCs were carried out at the calibration facility of the Leibniz Institute for Tropospheric Research, Leipzig, Germany.

The ratio between $n_{\text {det }}$ and the $n_{\text {real }}$ at a given particle size is defined as the counting efficiency $\eta\left(d_{p}\right)$ of a particle counter. The counting efficiency at which $\eta\left(d_{p}\right)=50 \%$ determines $d_{p 50}$. The $d_{p 50}$ can be determined as a function of the supersaturation and can be adjusted within a certain range by changing the temperature difference $\Delta T$ between the saturator $\left(T_{\text {Sat }}\right)$ and the condenser $\left(T_{\text {Cond }}\right)$.

An additional important parameter for CPC characterization is the pressure dependent maximum asymptotic counting efficiency. This parameter describes the plateau value of the counting efficiency for larger aerosol particles. Hermann and Wiedensohler (2001) showed for the Model 7610 (TSI Inc.), operated with butanol, that the maximum asymptotic counting efficiency decreases significantly with decreasing pressure for pressures below $300 \mathrm{hPa}$. However, Hermann et al. (2005) showed that the maximum asymptotic counting efficiency is close to 1 for $p<300 \mathrm{hPa}$ when FC-43 is used as working fluid inside the same CPC type.

Silver $(\mathrm{Ag})$ particles were used in this study to determine the counting efficiencies of the COPAS CPCs, as Ag particles can be produced easily in sufficiently high number concentration for particle diameters of a few nanometers
$(<4 \mathrm{~nm})$. Furthermore, silver particles can be generated in nearly spherical shape (Ku and Maynard, 2006) and they are physically stable and inert with respect to chemical reactions.

The calibration set-up used for the COPAS characterization is described in detail by Hermann and Wiedensohler (2001) and Hermann et al. (2005). The calibration aerosol is charged by a neutralizer $\left({ }^{241} \mathrm{Am}\right.$ source $)$ and a monodisperse fraction is selected by a Differential Mobility Analyzer (DMA, Vienna-type, short). The COPAS CPC is positioned parallel to an Aerosol Electrometer used as the reference counter. Both instruments are operated inside the low pressure part of the calibration set-up. For the COPAS characterization pressures from $70 \mathrm{hPa}$ to $300 \mathrm{hPa}$ were covered. The operating temperatures of the COPAS-I were $T_{\text {Sat }}=32^{\circ} \mathrm{C}$ and $T_{\text {Cond }}=2^{\circ} \mathrm{C}\left(\Rightarrow \Delta T=30^{\circ} \mathrm{C}\right)$, common for both channels. The channels 1 and 2 of COPAS-II were operated with $T_{\text {Sat }}=24^{\circ} \mathrm{C}$ and $T_{\text {Cond }}=7^{\circ} \mathrm{C}$ and $T_{\text {Sat }}=40^{\circ} \mathrm{C}$ and $T_{\text {Cond }}=7^{\circ} \mathrm{C}$ ( $\Rightarrow \Delta T_{1}=17^{\circ} \mathrm{C}$ and $\Delta T_{2}=33^{\circ} \mathrm{C}$ ), respectively. Resulting supersaturation factors from $\Delta T$ setting of each COPAS CPC are listed in Table 2.

Figure 4 A-D shows the results of the characterization of both COPAS CPCs for a particle sizes range of $5 \mathrm{~nm}<$ $d_{p}<35 \mathrm{~nm}$ for $p=70$ and $300 \mathrm{hPa}$. The error bars on the $\mathrm{x}$-axis represent theoretical values of the bandwidth of the DMA transfer function. The error bars on the y-axis display the standard deviation of the measurements. For each particle diameter and both pressure conditions four measurement points were recorded.

Table 2 summarizes the resulting $d_{p 50}$ dependent on $\Delta T$ for the COPAS channels for two pressure conditions. For the field measurements, the two channels of COPAS-I, with similar $d_{p 50} \approx 11 \mathrm{~nm}$, are used to study the non-volatile fraction of the total particle number concentration. The difference in the efficiency characteristic between the two COPAS-I channels results from the mounted (but not heated) heating line at channel 1 (see Fig. 4a). Two effects can be observed due to the elongated aerosol tube $-\mathrm{a}$ shift of $\mathrm{d}_{p 50}$ to larger sizes and a decreased maximum asymptotic counting efficiency for channel 1 (7-12\% lower compared to channel 2). These effects are caused by additional particle losses. Nevertheless, the decreased maximum asymptotic counting efficiency 

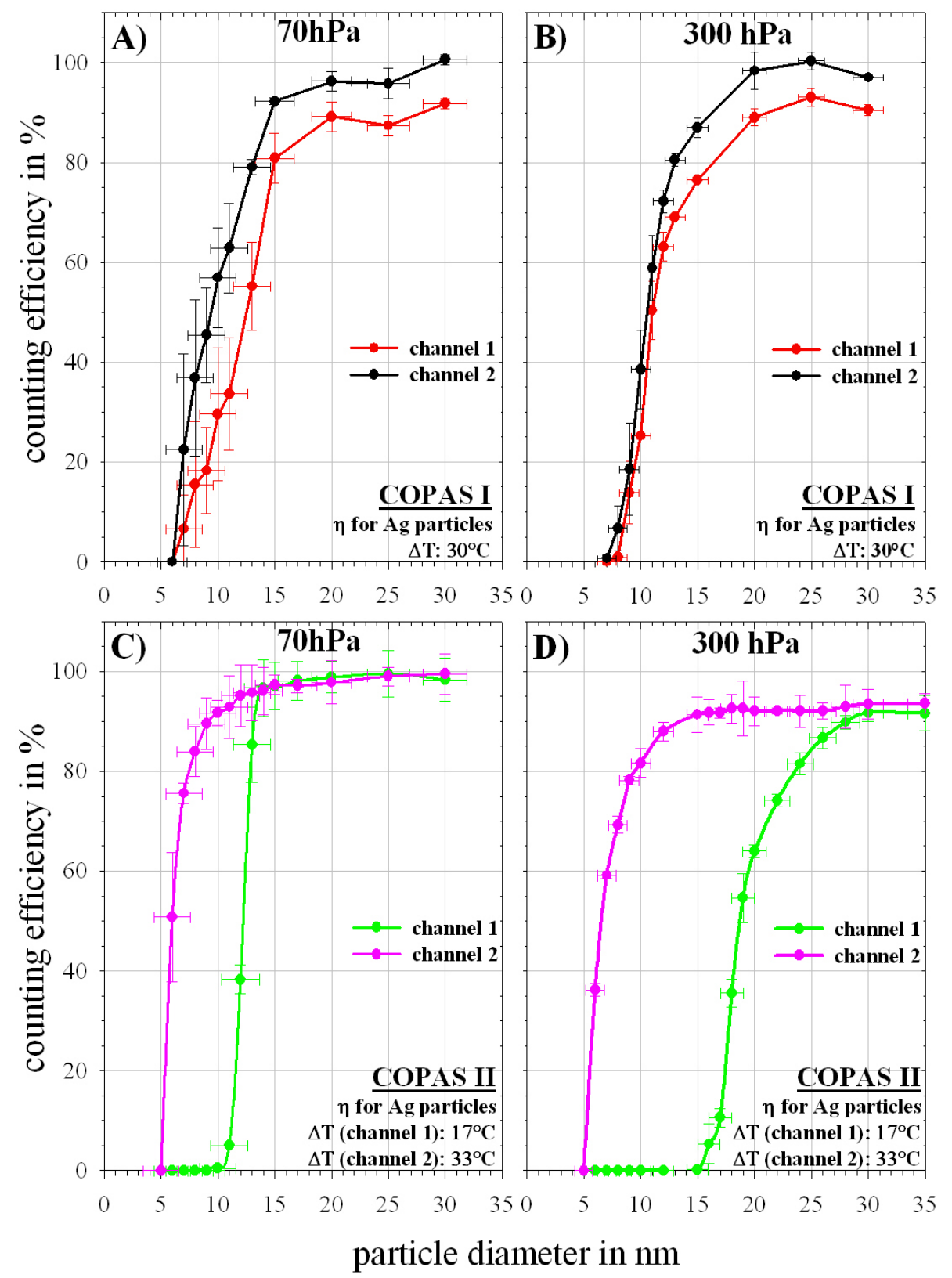

Fig. 4. Results of the experimental COPAS CPC counting efficiency characterizations compared to an Aerosol Electrometer at two different system pressures, $70 \mathrm{hPa}$ and $300 \mathrm{hPa}$. Graphs A) and B) show the counting efficiency curves of COPAS-I, channel 1 (red) and channel 2 (black) operating with a common $\Delta T$ of $30^{\circ} \mathrm{C}$. The mounted (but not heated) heating line at the aerosol tube of channel 1 and the associated additional particle losses explain the observed differences between the curves. Graphs C) and D) show the result of COPAS-II channel 1 (green) and channel 2 (pink) operated with different $\Delta T$.

yields a correction of the heated channel measurements of generally not more than $10 \%$.

The channels of COPAS-II have significantly different $d_{p 50}, d_{p 50} \approx 12 \mathrm{~nm}$ (at $70 \mathrm{hPa}$ ) for channel 1 (with increasing atmospheric pressure up to $d_{p 50} \approx 19 \mathrm{~nm}$ (at $300 \mathrm{hPa}$ ) and $d_{p 50} \approx 6 \mathrm{~nm}$ for channel 2 , nearly independent of pressure. For sake of simplicity, also a pressure independent mean $d_{p 50}$ of $15 \mathrm{~nm}$ for channel 1 is generally assumed. The difference between the two COPAS II channels is used to investigate the occurrence or absence of freshly nucleated aerosol particles in the atmosphere.

The accuracy of the COPAS measurements was also determined from the characterisation experiments. The total accuracy is estimated to be within $\pm 10 \%$. 
Table 3. Pressure dependent volume flow rates for the COPAS CPCs, according residence times for the aerosol particles inside the photo-optical detector volume and the coincidence parameter.

\begin{tabular}{cccc}
\hline $\begin{array}{c}\text { pressure } \\
p \text { in } \mathrm{hPa}\end{array}$ & $\begin{array}{c}\text { volume flow } \\
Q \text { in } \mathrm{cm}^{3} \mathrm{~s}^{-1}\end{array}$ & $\begin{array}{c}\text { residence time } \\
t \text { in } \mu \mathrm{s}\end{array}$ & $\begin{array}{c}\text { coincidence parameter } \\
c \times 10^{5} \mathrm{in}^{3}\end{array}$ \\
\hline 70 & 16.4 & 0.6 & 0.98 \\
150 & 10.1 & 1.0 & 1.01 \\
300 & 6.1 & 1.5 & 0.92 \\
600 & 4.0 & 2.5 & 1.00 \\
\hline
\end{tabular}

\section{Coincidence and homogeneous nucleation}

Coincidence describes the classification of two or more particles simultaneously present in a detection volume and therefore registered as one single particle (Raasch and Umhauer, 1984). We estimated the true particle number concentration $n_{\text {real }}$ from the measured particle number $n_{\text {det }}$ according to Jaenicke (1970, 1972); Hermann and Wiedensohler (2001) using the coincidence parameter of the optical detector $c=10^{-5} \mathrm{~cm}^{3}$ (TSI Incorporated, 2002) (cf. Table 3). For particle number densities below $\sim 10^{4} \mathrm{~cm}^{-3}$ coincidence is not influencing the counting results significantly. Such high concentrations are rarely encountered in the UT/LS. For the rare cases where the measured particle number concentration significantly exceeds $10^{4} \mathrm{~cm}^{-3}$, the measurements with COPAS are corrected by a factor $\kappa_{C}$ which is parameterized by $\kappa_{C}=\exp \left(1.23 \times 10^{-5} \cdot n_{\mathrm{det}}\right)$.

To determine the operational limits above which homogeneous nucleation of the CPC working fluid starts to occur (e.g. Hämeri et al., 1995), the temperature difference $\Delta T$ was increased stepwise when operating in particle-free conditions to check at which point a signal in the CPC occurs. At $50 \mathrm{hPa}$ significant particle concentrations were not observed until a $\Delta T$ of $42^{\circ} \mathrm{C}$ was reached. At $100 \mathrm{hPa}$, homogeneous nucleation occurred only for $\Delta T>47^{\circ} \mathrm{C}$. Therefore, for the range of temperature differences used for the COPAS instruments $\left(17-33^{\circ} \mathrm{C}\right)$, the process of homogeneous nucleation of the working fluid can be excluded.

\section{The particle volatilization efficiency of the heated channel}

Previous work on volatilization properties of aerosols, particularly oriented to the stratospheric $\mathrm{H}_{2} \mathrm{SO}_{4}-\mathrm{H}_{2} \mathrm{O}$ aerosol component, has been performed by Rosen (1971), Deshler et al. (1993), and Brock et al. (1995).

The volatizing behavior of the COPAS heating line was studied by laboratory experiments using a pure $\mathrm{H}_{2} \mathrm{SO}_{4}-\mathrm{H}_{2} \mathrm{O}$ calibration aerosol. Prior to the measurements, all inner surfaces of the stainless steel tubes of the calibration setup were

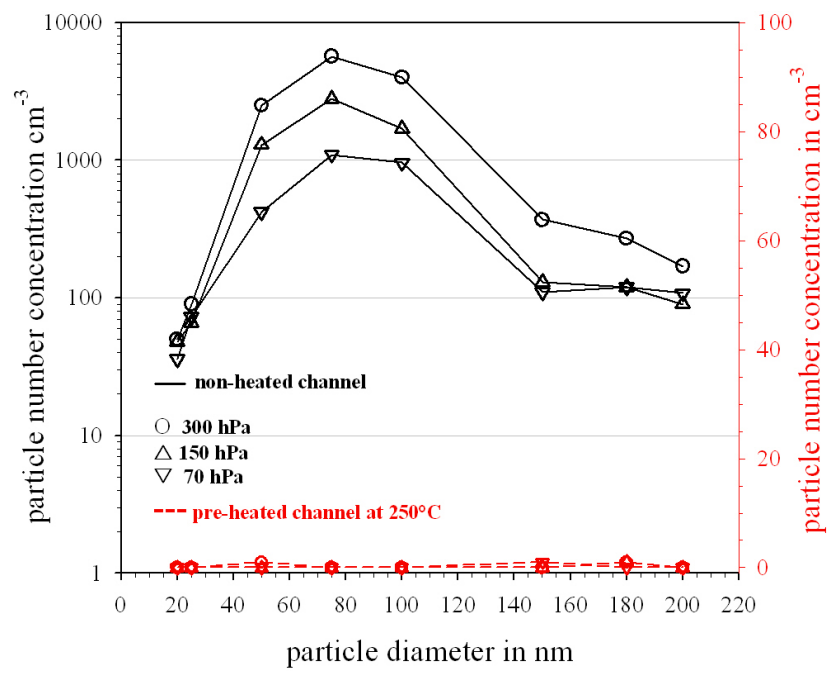

Fig. 5. Result of the experimental aerosol heating line characterization with pure $\mathrm{H}_{2} \mathrm{SO}_{4}-\mathrm{H}_{2} \mathrm{O}$ aerosol at a pre-heating temperature of $250^{\circ} \mathrm{C}$ for three operating pressures: $70 \mathrm{hPa}, 150 \mathrm{hPa}$, and $300 \mathrm{hPa}$. The comparison was made between the pre-heated (red) and the non-heated (black) channel of COPAS-I. Note the different scales of the ordinates.

cleaned with citric acid $\left(\mathrm{C}_{6} \mathrm{H}_{8} \mathrm{O}_{7}\right)$ to prevent contamination of the calibration aerosol by residues of, e.g., Ammonia. High purity nitrogen (5.0) was used as the carrier gas for the particles. The $\mathrm{H}_{2} \mathrm{SO}_{4}-\mathrm{H}_{2} \mathrm{O}$ particles were generated with a particle generator (Middlebrook et al., 1997; Böttger, 2000) by heating a small reservoir of 90 -weight-percent solution of $\mathrm{H}_{2} \mathrm{SO}_{4}$ and $\mathrm{H}_{2} \mathrm{O}$.

The freshly generated polydisperse aerosol was separated with an electrostatic classifier (Model 3080N, TSI Incorporated) and the size-selected calibration aerosol was transferred into a low pressure sampling volume via a critical orifice. For these experiments the results from the heated channel were compared with the measurements from the unheated channel of the COPAS I instrument, where both channels have a $d_{p 50}$ of $\sim 11 \mathrm{~nm}$ (see Fig. $4 \mathrm{a}$ and b). First studies at $70 \mathrm{hPa}$ showed that particles with $d_{p}=50 \mathrm{~nm}$ were volatilized to sizes smaller than the $d_{p 50}$ of COPAS-I already at heating temperatures of $176^{\circ} \mathrm{C}$. To insure the total volatilization of particles with sizes $d_{p}>50 \mathrm{~nm}$ the temperature of the COPAS aerosol heating line was set to $250^{\circ} \mathrm{C}$. For three pressures, i.e., $70 \mathrm{hPa}, 150 \mathrm{hPa}$, and $300 \mathrm{hPa}$, the heating efficiency was characterized for pure $\mathrm{H}_{2} \mathrm{SO}_{4}-\mathrm{H}_{2} \mathrm{O}$ aerosol particles in the size range of $20 \mathrm{~nm}<d_{p}<200 \mathrm{~nm}$. The results of the heating line characterization are shown in Fig. 5. At an operation temperature of $250^{\circ} \mathrm{C}$ and over the pressure range $70-300 \mathrm{hPa}$ the aerosol pre-heater volatilizes more than $98 \%$ of the $\mathrm{H}_{2} \mathrm{SO}_{4}-\mathrm{H}_{2} \mathrm{O}$ particles. Although, we were not able to generate $\mathrm{H}_{2} \mathrm{SO}_{4}-\mathrm{H}_{2} \mathrm{O}$ particles of sizes larger than $200 \mathrm{~nm}$ within this study we assumed from laboratory as well as field study experience that this volatilization 
efficiency of the aerosol pre-heater is also valid for particles with $d_{p}>200 \mathrm{~nm}$. This concept has been successfully applied for the differentiation of pure stratospheric sulphuric acid droplets from droplets containing residues of meteoric ablation (Curtius et al., 2005).

\section{Characterization experiments during flight operation}

A cross-correlation of the COPAS CPCs (Fig. 6) was performed to demonstrate the coherence of the measurements and to provide in-flight quality control. Therefore the data of altogether six measurement flights were used when all three unheated COPAS channels were operated on the M-55 with identical settings $\left(d_{p 50} \approx 10 \mathrm{~nm}\right)$. During these flights still all COPAS CPCs were operated with butanol as working fluid (Curtius et al., 2005), the COPAS setup has been changed for use of FC-43 after this campaign. The correlations were obtained using 15-s averaged data of particle number concentration by (1) inter-comparing the two CPC channels contained inside COPAS-II (Fig. 6a) and by (2) crosscomparing one CPC channel from COPAS-I with one channel from COPAS-II (Fig. 6b). The correlation coefficients of 0.996 (Fig. 6a) and 0.985 (Fig. 6b) illustrate a high level of consistency between the COPAS CPCs.

\section{Examples of arctic and tropical measurements}

Vertical profiles of the particle number concentration of two typical flights are shown in Fig. 7 to demonstrate the COPAS measurement results. These flights are chosen to discuss instrumental limitations with respect to flight conditions, particularly at low flight altitudes. In the graphs the particle number concentration is given as 15 -s averages. All particle number concentrations presented in this paper refer to ambient conditions.

The upper panel of Fig. 7 depicts a flight on 2 February 2003 (longitude: $10^{\circ}-30^{\circ}$ east; latitude: $68^{\circ}-76^{\circ}$ north) at Arctic regions during the EUropean Polar stratospheric cloud and Lee-wave EXperiment (EUPLEX). During this campaign both COPAS instruments were operated with the working fluid butanol and with the same differential temperatures $\Delta T$ yielding the same $d_{p 50}$ of $10 \mathrm{~nm}$ for all channels. In the lower panel of Fig. 7 data are shown from a flight on 12 February 2005 (longitude: $41^{\circ}-51^{\circ}$ west; latitude: $17^{\circ}-21^{\circ}$ south) during the Tropical Convection, CIrrus and Nitrogen OXides Experiment (TROCCINOX), when both COPAS instruments were operated with FC-43 as the working fluid. The $\Delta T$ for each of the non-heated CPCs was set to yield $d_{p 50}=6 \mathrm{~nm}\left(n_{6}\right), d_{p 50}=11 \mathrm{~nm}\left(n_{11}\right)$, and $d_{p 50}=15 \mathrm{~nm}\left(n_{15}\right)$, respectively (cf. Sect. 4). COPAS-I measured the total number concentration $n_{11}$ as well as the non-volatile particle number $\left(n_{11 \mathrm{nv}}\right)$. On the right side of each panel the respective fraction of non-volatile particles is shown.

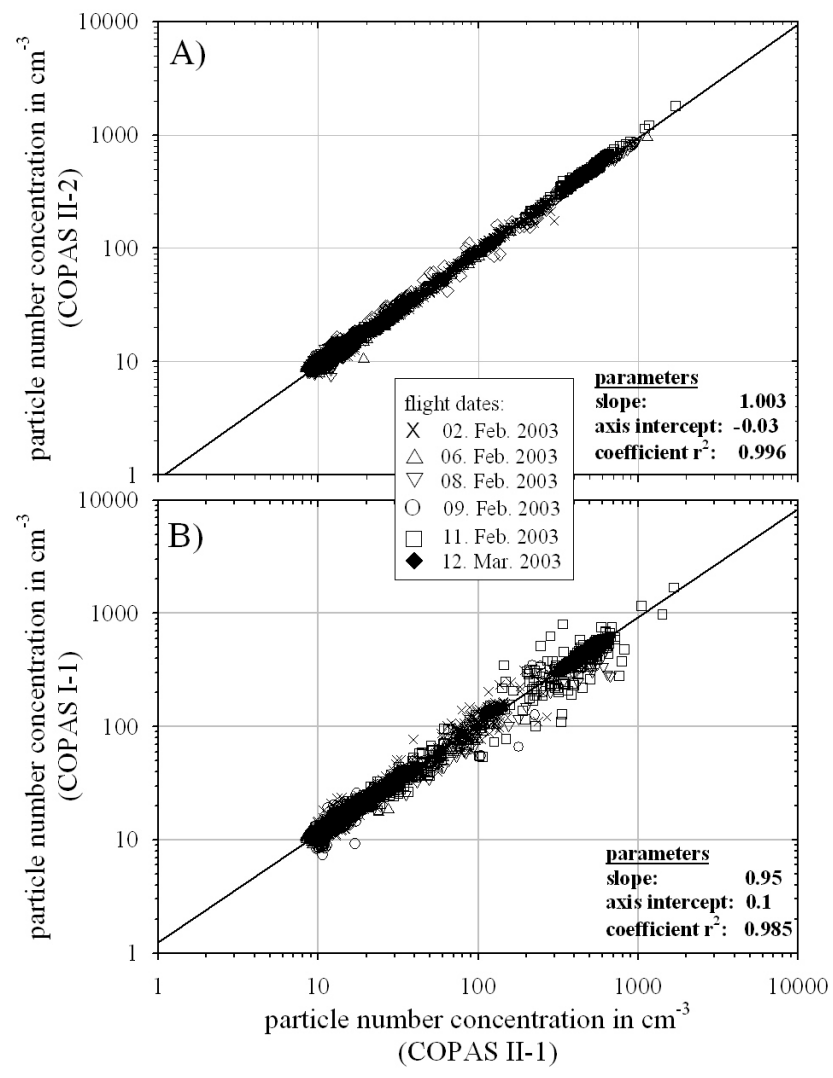

Fig. 6. Correlation of COPAS ambient particle number density measurements (15 s average) from six flights in the arctic lower stratosphere when both COPAS instruments were operated with butanol as well as the same $\Delta T$ and therefore identical $d_{p 50}$. (A) COPASII inter-comparison between two channels of the same instrument with a correlation coefficient of 0.996. (B) Cross-comparison between one channel of COPAS-I and one channel of COPAS-II with a correlation coefficient of 0.985 (adapted from Curtius et al., 2005).

The example from our tropical measurements yields good agreement (not graphically illustrated herein) with previously published tropical vertical particle distributions (Brock et al., 1995) up to UT/LS altitudes for undisturbed stratospheric conditions. The polar measurements show the difference between the conditions in polar tropospheric air $(\Theta<$ $370 \mathrm{~K}$ - influenced by air masses from lower latitudes) and polar vortex air masses $(\Theta>380 \mathrm{~K}-$ nearly isolated from influences of lower latitudes).

From the profile of the non-volatile aerosol fraction during the arctic measurements the enhanced particle number at $\Theta>435 \mathrm{~K}$ is assumed to mainly contain non-volatile material $(50 \%$, and with increasing altitude up to $70 \%)$. For detailed discussions concerning this observation inside the polar winter vortex see Curtius et al. (2005). The non-volatile particle fraction of the tropical measurements decreases well below $50 \%$ above the tropical tropopause, and above a transition region $(\Theta>400 \mathrm{~K})$ a nearly constant value of about 

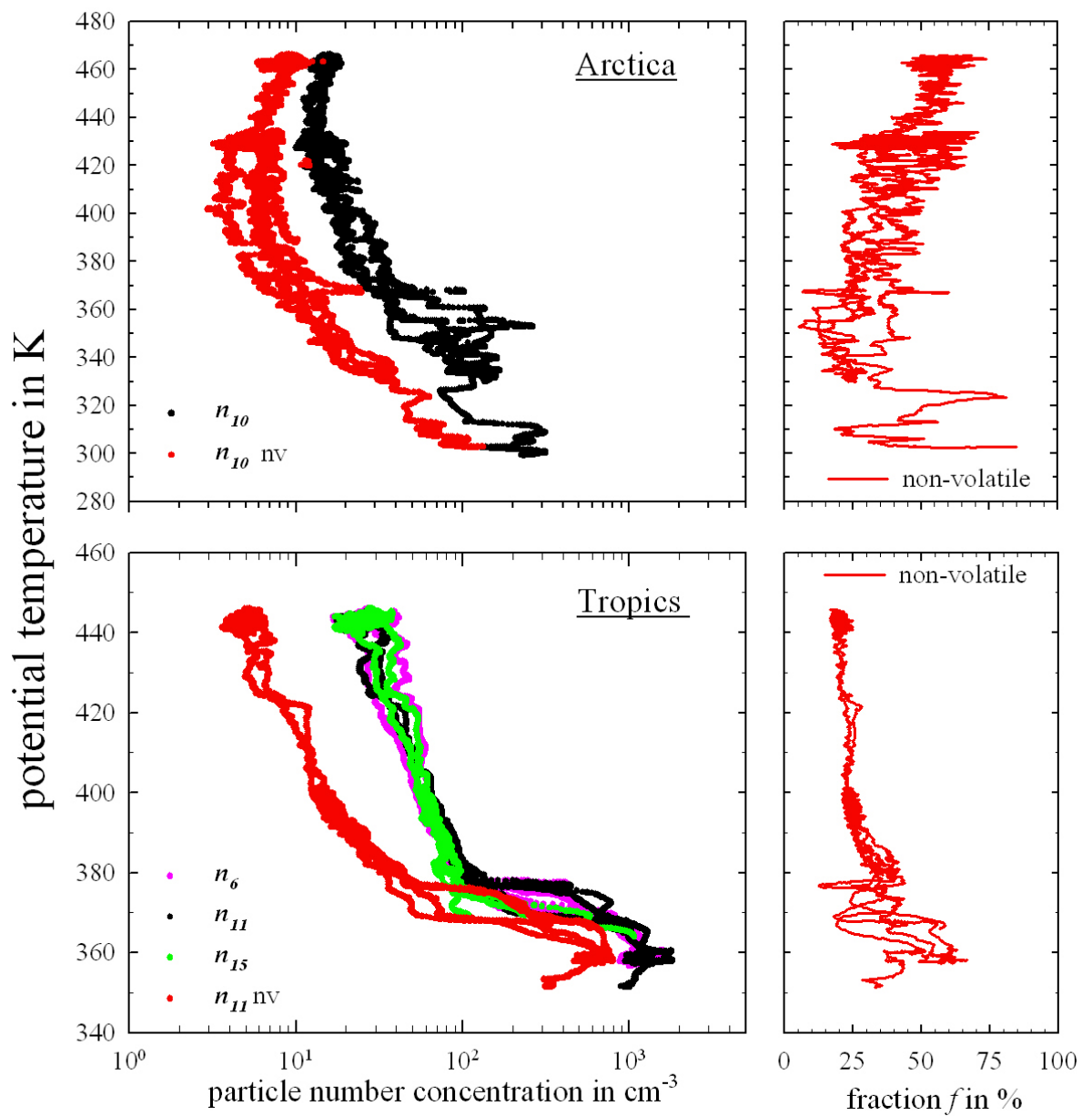

Fig. 7. Vertical profiles of particle number concentration (left) and the vertical distribution of the non-volatile aerosol fraction (right) measured by COPAS at two different measurement locations. Data are shown as 15 -s running averages versus potential temperature as the vertical coordinate. Upper panel: Flight example from 2 February 2003 (longitude: $10^{\circ}-30^{\circ}$ east; latitude: $68^{\circ}-76^{\circ}$ north) during the polar mission EUPLEX. COPAS working fluid: butanol. Lower panel: Flight example from 12 February 2005 (longitude: $41^{\circ}-51^{\circ}$ west; latitude: $17^{\circ}-21^{\circ}$ south) during the tropical mission TROCCINOX. COPAS working fluid: FC-43.

$25 \%$ for the non-volatile aerosol fraction is found. While for the measurements inside the polar vortex the non-volatile material is transported mainly from higher (mesospheric) altitudes with subsiding air masses, at tropical latitudes the non-volatile particle fraction is most likely maintained by transport processes between the Tropical Tropopause Layer (TTL) and the stratosphere (Hamill at al., 1997).

The COPAS data do not extend down to ground level. The measurements from ground level to altitudes of 7-12 km have to be analyzed carefully with respect to data quality. For the particular cases measurement data from flight altitudes lower than $7.5 \mathrm{~km}(\Theta=300 \mathrm{~K}$ for the polar measurement $)$ and $11.5 \mathrm{~km}(\Theta=350 \mathrm{~K}$ at tropical latitudes) were rejected if one of the following three aspects limited the COPAS measurements:

1. the automated flow regulation of COPAS did not work properly caused by fast ascent or descent rates of $>10 \mathrm{~m} \mathrm{~s}^{-1}$.
2. high ambient temperatures at the ground prior to the flights prevented the cooling system of the COPAS condensers to work efficiently immediately after take-off, e.g., for the measurement presented in Sect. 2.3 the condenser cooling circuit was not working properly until the aircraft reached an altitude of $12 \mathrm{~km}$.

3. using FC-43 as the working fluid, at ambient pressures $>400 \mathrm{hPa}$ the $\mathrm{CPC} d_{p 50}$ as well as the maximum asymptotic counting efficiency can change significantly (cf. Hermann et al., 2005).

\section{Aerosol observation in M-55 plumes}

Several observations of enhanced particle number concentration during two research flights during the TROCCINOX and the SCOUT missions were caused by crossings of the M-55 own exhaust at altitudes between 16 and $18 \mathrm{~km}$. The 


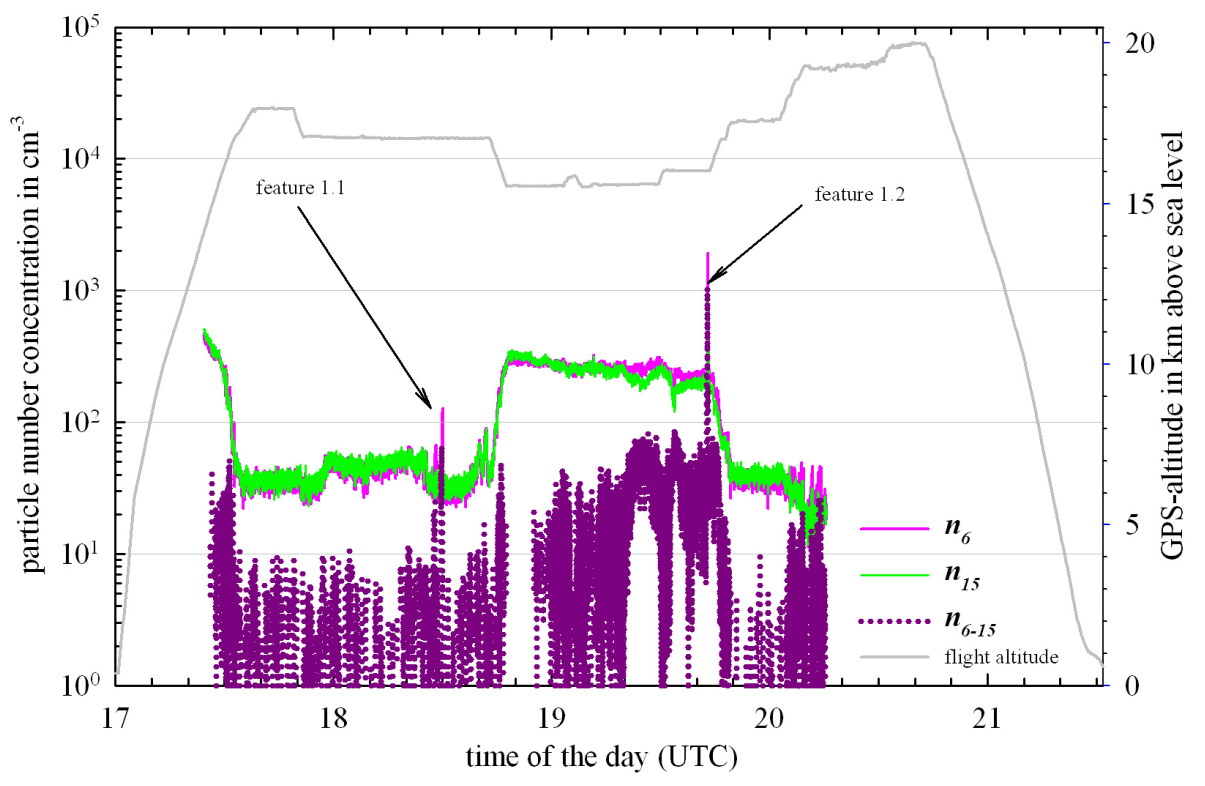

Fig. 8. Time series of COPAS measurements during the flight on 5 February 2005 (longitude: $48^{\circ}-54^{\circ}$ west; latitude: $19^{\circ}-22^{\circ}$ south). Displayed are the measured ( $1 \mathrm{~Hz}$ ) ambient particle number concentration $n_{6}$ (pink) and $n_{15}$ (green) of COPAS-II as well as the GPS-altitude during the flight (grey line). Two observations of enhanced particle number concentrations are denoted as feature 1.1 and feature 1.2. Additionally, the time series of the ultra-fine particle number concentration difference between $n_{6}$ and $n_{15}$ ( $n_{6-15}$ ) (purple dots) is shown, corrections for coincidence and for particle losses inside the sample lines have been applied.

plumes were identified by simultaneous short term increases in the particle number concentrations and the concentration of nitrogen oxides $\left(\mathrm{NO}_{\mathrm{x}}=\mathrm{NO}+\mathrm{NO}_{2}\right)$ detected by the German Aerospace Center (DLR) using a chemiluminescence technique. The $\mathrm{NO}_{\mathrm{x}}$ instrument on board the M-55 is described in detail by Voigt et al. (2006). We can exclude civil aviation as potential source of these particle and $\mathrm{NO}_{\mathrm{x}}$ enhancements, as the plumes were detected at altitudes between 16 and $18 \mathrm{~km}$, more than $4 \mathrm{~km}$ above the cruise altitudes of commercial aircraft. Additional confidence in the plume crossings was given by air mass back trajectories calculations (Corti et al., 2008, or HYSPLIT (http://www.arl.noaa.gov/ready/hysplit4. html)). This combined evidence from in situ data und trajectory modelling also suggests that it is unlikely, that the enhancements were caused by lightning.

The $1 \mathrm{~Hz}$ - time series of the particle number concentration measured with COPAS-II during a tropical flight on 5 February $2005\left(48^{\circ}-54^{\circ} \mathrm{W}, 19^{\circ}-22^{\circ} \mathrm{S}\right)$ of the TROCCINOX mission is shown in Fig. 8. The ultra-fine particle number concentration $n_{6-15}$ was calculated and was corrected for diffusional losses $\left(\kappa_{L}=1.28\right.$, cf. Sect. 3.3 and Table 1). Two distinct increases, feature 1.1 and 1.2 , in particle concentration occur in this time series. Due to instrumental background measurements of the $\mathrm{NO}_{\mathrm{x}}$ instrument during feature 1.1 we refrain from a detailed discussion of feature 1.1. Feature 1.2 is caused by the crossing of M-55 exhaust as supported by simultaneous particle and $\mathrm{NO}_{\mathrm{x}}$ enhancements. For this feature, the plume age was estimated to be in the range of $8000 \mathrm{~s}$ from the trajectory calculations.
The second example is taken from a flight on 25 November $2005\left(127^{\circ}-132^{\circ} \mathrm{E}, 9^{\circ}-13^{\circ} \mathrm{S}\right)$ during the mission Stratosphere-Climate Links with Emphasis On the Upper Troposphere and Lower Stratosphere (SCOUT-O ${ }_{3}$ ), see Fig. 9. Figure 10 shows the flight track of the M-55 indicating a high probability of exhaust crossing. We further focus on feature 2.3 with an estimated plume age of $2600 \mathrm{~s}$ to make use of the simultaneous $\mathrm{NO}_{\mathrm{x}}$ measurements, while $\mathrm{NO}_{\mathrm{x}}$ data were not enhanced for features 2.1 and 2.2.

We determine the particle emission indices $E I[n]$ of the M-55 aircraft engines at UT/LS conditions using the measured enhancement in $\mathrm{NO}_{\mathrm{x}}$ mixing ratios inside aircraft exhaust as a normalizing factor. This method has already been applied for other aircraft (Fahey et al., 1995a, b; Schlager et al., 1997; Anderson et al., 1999), particularly for plume ages in the range of hours. The $E I[n]$ of an aircraft engine, in units of particle number per $\mathrm{kg}$ fuel burned, was calculated by using following equation (Anderson et al., 1999).

$E I\left[n_{i}\right]=\left(\frac{\Delta n_{i}}{\Delta \mathrm{NO}_{\mathrm{x}}}\right) \cdot E I\left[\mathrm{NO}_{\mathrm{x}}\right] \cdot \frac{M_{\mathrm{air}}}{\left(\rho \cdot M_{\mathrm{NO}_{2}}\right)}$

where:

$\Delta n_{i}=$ particle number concentration in the plume related to background concentrations in $\mathrm{cm}^{-3}$, the index $i$ distinguishes the CPC $d_{p 50}$

$\Delta \mathrm{NO}_{\mathrm{x}}=$ differential $\mathrm{NO}_{\mathrm{x}}$ mixing ratio in the plume related to background values, in ppt

$M=$ molecular Mass, $M_{\mathrm{air}}=29 \mathrm{u}, M_{\mathrm{NO} 2}=46 \mathrm{u}$ 


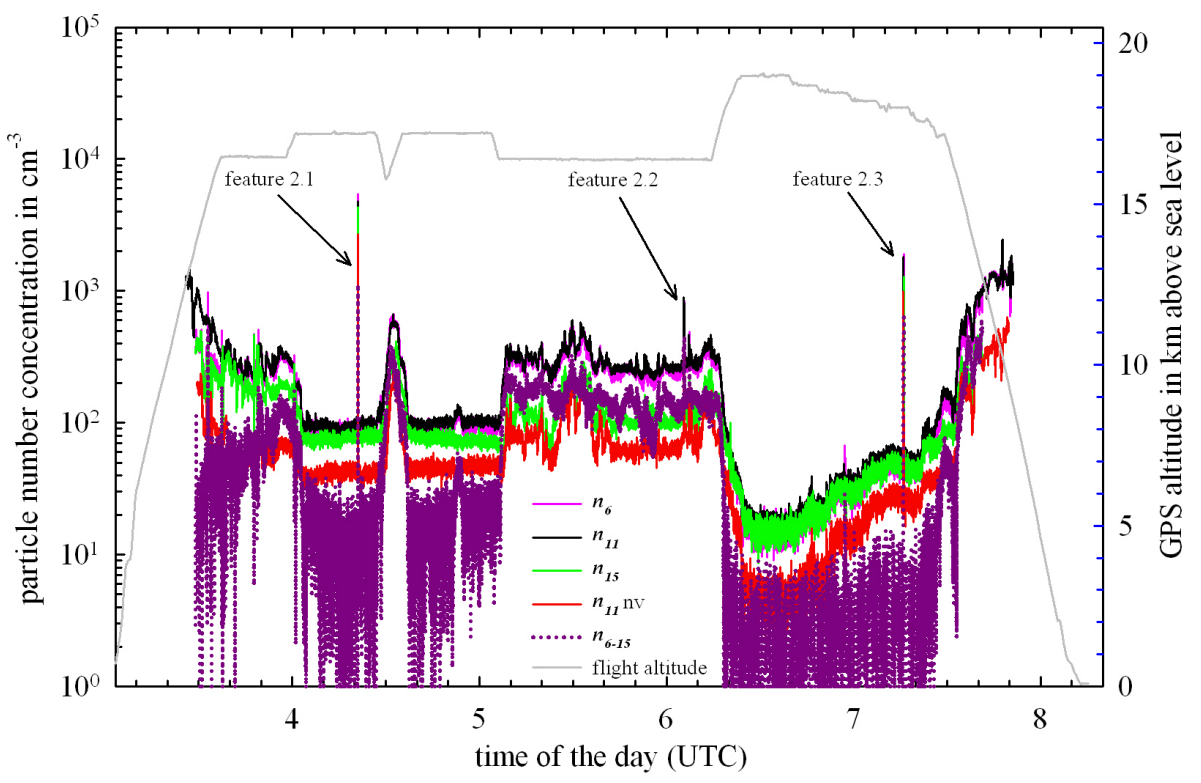

Fig. 9. Time series of COPAS measurements during the flight on 25 November 2005 (longitude: $127^{\circ}-132^{\circ}$ east; latitude: $9^{\circ}-13^{\circ}$ south). Displayed are the measured particle number concentration $n_{6}$ (pink), $n_{11}$ (black), and $n_{15}$ (green) as well as $n_{10} \mathrm{nv}$ (red) and $n_{6-15}$ (purple dots), corrections for coincidence and for particle losses inside the sample lines have been applied. The GPS-altitude during the flight is indicated (grey). Three observations of enhanced particle number concentrations are denoted as feature 2.1, 2.2 and feature 2.3.

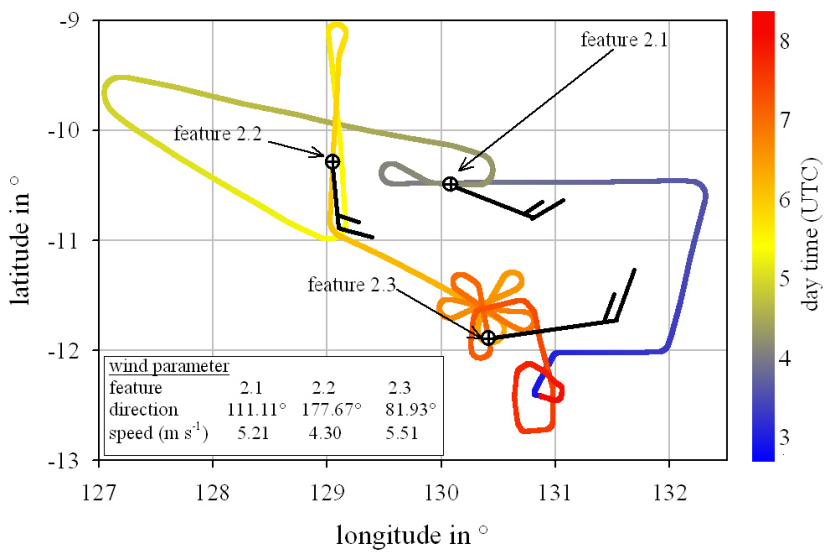

Fig. 10. Projection of the flight path for 25 November 2005. The flight path is shown coloured dependent on flight time, potential plume encounters are labelled as feature $2.1,2.2$, and 2.3 , respectively.

$\rho=$ air density, in $\mathrm{kg} \mathrm{m}^{-3}$, at flight conditions during observed event.

The integrated signal $(\Delta X)$ of observed enhancement of a species $\mathbf{X}$ related to background conditions is given as:

$\Delta X=\Delta t_{\text {obs }}\left(X_{\text {plume }}-X_{0}\right)$

Here, $\Delta t_{\mathrm{obs}}$ is the duration of an enhancement observation and the bracket term is the difference of measured number concentrations, or mixing ratio, inside the plume $\left(X_{\text {plume }}\right)$ related to background conditions outside the plume $\left(X_{0}\right)$.
An order of magnitude estimate of the $E I\left[n_{i}\right]_{\mathrm{M}-55}$ has been derived from the particle number measurements and a comparison of the $E I\left[\mathrm{NO}_{\mathrm{x}}\right]$ of the M-55 and the NASA ER2 high altitude research aircraft. Fahey et al. (1995b) determined an $E I\left[\mathrm{NO}_{\mathrm{x}}\right]_{\mathrm{ER}-2}$ of the NASA ER-2 at cruising flight condition of about $3.6-4.3 \mathrm{~g} \mathrm{~kg}^{-1}$.

The fuel consumption of the M-55 has been recorded during flight. As the aircraft was ascending, the fuel consumption was increased by a factor of 1.8 compared to cruise during feature 1.2, indicative for engine's full-load operation. This full-load operation of aircraft engines might change the fuel-to-oxygen ratio inside the turbines, causing inefficient fuel burning and enhanced emission indices compared to cruising conditions. For feature 2.3 at cruise the fuel consumption equals $846 \mathrm{~kg} \mathrm{~h}^{-1}$. As an approximation for this study, the $\mathrm{NO}_{\mathrm{x}}$ emission index for the M55 is estimated to $E I\left[\mathrm{NO}_{\mathrm{x}}\right]_{\mathrm{M}-55}=1-1.5 \cdot E I\left[\mathrm{NO}_{\mathrm{x}}\right]_{\mathrm{ER}-2}=3.6-$ $6.5 \mathrm{~g} \mathrm{~kg}^{-1}$. This value is comparable to $\mathrm{NO}_{\mathrm{x}}$ emission indices for small jet aircraft, e.g. the DLR Attas VFW614 with $E I\left[\mathrm{NO}_{\mathrm{x}}\right]_{\text {Attas }} \approx 7 \mathrm{~g} \mathrm{~kg}^{-1}$, the Boeing B737 with $E I\left[\mathrm{NO}_{\mathrm{x}}\right]_{B 737}=9.4-11.4 \mathrm{~g} \mathrm{~kg}^{-1}$ (Schulte et al., 1997), or the Boeing B727 with $E I\left[\mathrm{NO}_{\mathrm{x}}\right]_{B 727}=7.7 \mathrm{~g} \mathrm{~kg}^{-1}$ (Schumann et al., 1998).

The ultra-fine particle number concentration $n_{6-15}$ as well as $n_{6}$ and $n_{15}$ were used to determine the $E I\left[n_{i}\right]_{\mathrm{M}-55}$ from the plume 1.2 encounter related to background concentrations $n_{o}$ outside of the plume were: $n_{6}=1930 \mathrm{~cm}^{-3}$ (for $n_{o}=220 \mathrm{~cm}^{-3}$ ), $n_{15}=880 \mathrm{~cm}^{-3}$ (for $n_{0}=180 \mathrm{~cm}^{-3}$ ), and $n_{6-15}=1050 \mathrm{~cm}^{-3}$ (for $n_{o}=50 \mathrm{~cm}^{-3}$ ) for $5 \mathrm{~s}$ maximum 
Table 4. Particle EI values for the M-55 Geophysika estimated from two crossings of the own exhaust plume at different plume ages (pa) in relation to according EI of other high altitude reaching aircraft, the NASA ER-2 (Anderson et al., 1999) and the Concorde (Fahey et al., $1995 \mathrm{a})$ - other $d_{p 50}$ than given for COPAS are denoted within brackets behind the EI value.

\begin{tabular}{cccccc}
\hline EI $\left[n_{i}\right] \times 10^{16}$ & \multicolumn{2}{c}{ M-55 Geophysika } & \multicolumn{2}{c}{ NASA ER-2 } & Concorde \\
$\mathrm{kg}^{-1}$ fuel burned & feature 1.2 pa: $8000 \mathrm{~s}$ & feature $2.3 \mathrm{pa:} 2600 \mathrm{~s}$ & pa: $8000 \mathrm{~s}$ & pa: $\sim 2600 \mathrm{~s}$ & averages for pa: 960-3480 \\
\hline$E I\left[n_{6}\right]$ & $3.5-6.3$ & $4.7-8.4$ & $13\left(n_{8}\right)$ & $10.4\left(n_{8}\right)$ & $17-65\left(n_{8}\right)$ \\
$E I\left[n_{11}\right]$ & - & $4.4-8.0$ & & & - \\
$E I\left[n_{15}\right]$ & $1.4-2.6$ & $3.1-5.6$ & $14.4\left(n_{17}\right)$ & $9\left(n_{17}\right)$ & - \\
$E I\left[n_{6-15}\right]$ & $2.0-3.7$ & $2.1-3.8$ & - & - & - \\
$E I\left[n_{11} \mathrm{nv}\right]$ & & $2.4-4.4$ & $0.43\left(n_{17} \mathrm{nv}\right)$ & $0.3\left(n_{17} \mathrm{nv}\right)$ & $7.2\left(n_{8} \mathrm{nv}\right)$ \\
\hline
\end{tabular}

particle enhancement in the plume. The total plume encounter lasted $18 \mathrm{~s}$ in the aerosol data and $20 \mathrm{~s}$ as derived from $\mathrm{NO}_{\mathrm{x}}$ data with a $\Delta \mathrm{NO}_{\mathrm{x}}$ of $150 \mathrm{ppt}$.

Measured maxima of the $n_{i}$ during the plume $2.3 \mathrm{ob}-$ servation are $n_{6}=1910 \mathrm{~cm}^{-3}$ and $n_{15}=1280 \mathrm{~cm}^{-3}$ (both for $\left.n_{o}=47 \mathrm{~cm}^{-3}\right), n_{6-15}=830 \mathrm{~cm}^{-3}$ at a background concentration of $<10 \mathrm{~cm}^{-3}, n_{11}=1820 \mathrm{~cm}^{-3}$ (for $n_{o}=50 \mathrm{~cm}^{-3}$ ) and $n_{11} \mathrm{nv}=990 \mathrm{~cm}^{-3}$ (for $n_{o}=25 \mathrm{~cm}^{-3}$ ). Here the observed $\mathrm{NO}_{\mathrm{x}}$ enhancement amounts to $\Delta \mathrm{NO}_{\mathrm{x}}=80 \mathrm{ppt}$ for $25 \mathrm{~s}$.

Based on these data, we determine the $E I\left[n_{i}\right]_{\mathrm{M}-55}$ between $1.4-8.4 \times 10^{16}$ particles per $\mathrm{kg}$ fuel as listed in Table 4 for both cases. Generally, the $E I\left[n_{i}\right]$ for both the M-55 and the NASA ER-2 are of similar magnitude. However, an uncertainty of about $\pm 50 \%$ has to be considered for the calculated $E I\left[n_{i}\right]_{\mathrm{M}-55}$ mainly caused by the uncertainty of estimated $E I\left[\mathrm{NO}_{\mathrm{x}}\right]_{\mathrm{M}-55}$. Further, aerosol processing, particularly in the ultra-fine size mode, within a time span of up to $8000 \mathrm{~s}$ has significant influence on the accuracy of calculated $E I\left[n_{i}\right]_{\mathrm{M}-55}$. Despite large uncertainties, our analysis presents the first order of magnitude estimate of the $E I\left[n_{i}\right]_{\mathrm{M}-55}$ for the high altitude research aircraft M-55.

\section{Summary}

A description and characterization of the two COndensation PArticle counting Systems (COPAS) for aircraft-borne measurements on board the high altitude research aircraft M-55 has been presented. The two COPAS units, designed for aerosol concentration measurements in the UT/LS region, include two CPCs each. Three CPC channels are usually operated with different $\Delta T$ settings inside the counters in order to have three different $d_{p 50}$ of 6,11 , and $15 \mathrm{~nm}$. Thereby the number concentration of ultra-fine, freshly nucleated particles can be derived in addition to measurement of the total particle number concentration. The fourth CPC channel is operated with an aerosol pre-heater to quantify the nonvolatile fraction of the aerosol particles. Overall, COPAS proved to be a reliable and robust instrument for aircraftborne particle concentration measurements in the UT/LS region.

The performance of the COPAS aerosol inlet, constructed for operation on the M-55, has been discussed with respect to particle aspiration, transmission, and transport. Concerning aspiration and transmission of the COPAS aerosol inlet it is estimated that particles with diameters of up to one micrometer enter the aerosol inlet and pass the aerosol lines without significant particle losses. However, concerning the transmission efficiency of the aerosol inlet, only additional wind tunnel studies could provide a complete characterization. Furthermore, in such wind tunnel studies, it should also be investigated whether the use of a shroud would be beneficial (Baumgardner et al., 1991; Murphy and Schein, 1998; Twohey, 1998; Weber et al., 1998). Particle losses inside the inlet system are assumed to be negligible for particle sizes smaller than $500 \mathrm{~nm}$.

The counting efficiency as a function of particle size and pressure was determined for each of the four COPAS CPC channels. The result of this CPC characterization allows for setting the $d_{p 50}$ to different particle sizes. For our measurements, the $d_{p 50}$ sizes were typically set to $d_{p 50}=6 \mathrm{~nm}$ (COPAS-II-2), $d_{p 50}=11 \mathrm{~nm}$ (COPAS-I-2) and $d_{p 50}=15 \mathrm{~nm}$ (COPAS-II- 1$)$. From the readings of the three counters, recent nucleation events can be identified by subtraction. The aerosol pre-heater (upstream of COPAS-I-1 with $d_{p 50}=11 \mathrm{~nm}$ ), which was characterized with respect to its ability to completely vaporize pure $\mathrm{H}_{2} \mathrm{SO}_{4}-\mathrm{H}_{2} \mathrm{O}$ particles, allows for physico-chemical aerosol studies concerning the volatility of the UT/LS aerosol. A pre-heating temperature of $250^{\circ} \mathrm{C}$ was chosen to volatilize the main component of UT/LS aerosol, namely $\mathrm{H}_{2} \mathrm{SO}_{4}-\mathrm{H}_{2} \mathrm{O}$.

The performance of the COPAS instruments was demonstrated in several case studies. Cross-correlation of two COPAS channels, for two channels of the same COPAS and for two channels of two independent COPAS instruments, 
illustrates the high consistency of the COPAS measurements. Two typical flight examples were used to describe the results from the COPAS measurements and the instrumental limitations with respect to flight altitude.

High ascent and descent rates of the measurement platform have significant impact on the performance of the COPAS particularly at low flight altitudes. Ascent and descent rates exceeding $10 \mathrm{~m} \mathrm{~s}^{-1}$ up to flight altitudes of $7-12 \mathrm{~km}$ significantly impact the reliability of COPAS measurements.

Finally, particle emission indices $E I\left[n_{i}\right]_{M-55}$ were estimated for the M-55 from two plume crossings, identified by enhanced particle number concentrations and simultaneously increased $\mathrm{NO}_{\mathrm{x}}$ mixing ratio. The estimated average $E I\left[n_{i}\right]_{\mathrm{M}-55} \approx 5 \times 10^{16} \mathrm{~kg}^{-1}$ fuel burned is comparable to results of the NASA ER-2.

Acknowledgements. We are thankful to V. Dreiling and C. Schrörs for their earlier preparatory work. We thank F. Helleis, M. Flanz, and $\mathrm{W}$. Schneider for the development of the COPAS electronics and K.-H. Bückart and the mechanical workshop of the MPIChemistry for technical support. We thank Stefano Balestri, APE-GAIA, the entire M-55 Geophysika crew, and the pilots in particular. The technological support of J. C. Wilson (University of Denver, Colorado, USA) and C. A. Brock (NOAA Laboratories, Boulder, Colorado, USA) for design and aircraft implementation are gratefully acknowledged. This work was supported by the European research projects EUPLEX (EVK2-2001-00084), APE-Infra (EVR1-CT-2001-40020), TROCCINOX (EVK2-2001-00122), and SCOUT-O $_{3}$ (GOCE-CT-2004-505390). The work of C. Voigt was funded by the HGF in the frame of the Junior Research Group AEROTROP. We thank T. Corti for trajectory calculations and $\mathrm{H}$. Schlager for providing $\mathrm{NO}_{\mathrm{x}}$ data. Two anonymous reviewers and the Editor F. Boersma are acknowledged for their valuable contributions during the submission process of this manuscript.

The service charges for this open access publication have been covered by the Max Planck Society.

Edited by: F. Boersma

\section{References}

Anderson, B. E., Corer, W. R., Crawford, J., Gregory, G. L., Vay, S. A., Brunke, K. E., Kondo, Y., Koike, M., Schlager, H., Baughcum, S. L., Jensen, E., Yongjing Zhao, and Kazuyuki Kita: An assessment of aircraft as a source of particles to the upper troposphere, J. Geophys. Res., 26(20), 3069-3072, 1999.

Arnold, F., Curtius, J., Speng, S., and Deshler, T.: Stratospheric aerosol sulfuric acid: First in situ measurements using a novel balloon-based mass spectrometer apparatus, J. Atmos. Chem., 30, 3-10, 1998

Baron, P. A. and Willeke, K.: Aerosol Measurement: Principles, Techniques and Applications, 2. Edition, John Wiley \& Sons, New York, 2001.

Baumgardner, D., Huebert, B., and Wilson, C.: Meeting review: Airborne aerosol inlet workshop, NCAR Technical Note TN362+1A, 288 pp., 1991.
Borrmann, S., Solomon, S., Dye, J. E., Baumgardner, D., Kelly, K. K., and Chan, K. R.: Heterogeneous reactions on stratospheric background aerosol, volcanic sulfuric acid droplets, and type 1 polar stratospheric clouds: Effect of temperature fluctuations and differences in particle phase, J. Geophys. Res., 102(D3), 36393648, 1997.

Böttger, T.: Aufbau einer Anlage zur Beschichtung luftgetragener Aerosolpartikel mit $\mathrm{H}_{2} \mathrm{O}$ und $\mathrm{H}_{2} \mathrm{SO}_{4}$, Diploma thesis at the Faculty of Mechanical Engineering, University of Applied Sciences, Aachen, 2000.

Brock, C. A., Hamill, P., Wilson, J. C., Jonsson, H. H., and Chan, K. R.: Particle formation in the upper Tropical Troposphere: A source of nuclei for the stratospheric aerosol, Science, 270, 1650-1653, 1995.

Carslaw, K. S., Luo, B. P., Clegg, S. L. Peter, T., Brimblecombe, P., and Crutzen, P. J.: Stratospheric Aerosol Growth and $\mathrm{HNO}_{3}$ Gas Phase Depletion from Coupled $\mathrm{HNO}_{3}$ and Water Uptake by Liquid Particles, Geophys. Res. Lett., 21(23), 2479-2482, 1994.

Cofer, W. R., Anderson, B. E., Winstead, E. L., and Bagwell, D. R.: Calibration and demonstration of a condensation nuclei counting system for airborne measurements of aircraft exhausted particles, Atmos. Environ., 32, 169-177, 1998.

Corti, T., Luo, B. P., de Reus, M., Brunner, D., Cairo, F., Mahoney, M. J., Martucci, G., Matthey, R., Mitev, V., dos Santos, F. H., Schiller, C., Shur, G., Sitnikov, N. M., Spelten, N., Vössing, H. J., Borrmann, S., and Peter, T.: Unprecedented evidence for deep convection hydrating the tropical stratosphere, Geophys. Res. Lett., 35, L10810, doi:10.1029/2008GL033641, 2008.

Curtius, J., Weigel, R., Vössing, H.-J., Wernli, H., Werner, A., Volk, C.-M., Konopka, P., Krebsbach, M., Schiller, C., Roiger, A., Schlager, H., Dreiling, V., and Borrmann, S.: Observations of meteoric material and implications for aerosol nucleation in the winter Arctic lower stratosphere derived from in situ particle measurements, Atmos. Chem. Phys., 5, 3053-3069, 2005, http://www.atmos-chem-phys.net/5/3053/2005/.

Cziczo, D. J., Thomson, D. S., and Murphy, D. M.: Ablation, flux, and atmospheric implications of meteors inferred from stratospheric aerosol, Science, 291, 1772-1775, 2001.

Deshler, T., Johnson, B. J., and Rozier, W. R.: Balloonborne measurements of Pinatubo aerosol during 1991 and 1992 at $41^{\circ} \mathrm{N}$ : Vertical profiles, size distribution, and volatility, Geophys. Res. Lett., 20, 1435-1438, 1993.

Deshler, T., Hervig, M. E., Kröger, C., Hofmann, D. J., Rosen, J. M., and Liley, J. B.: Thirty years of in situ stratospheric aerosol size distribution measurements from Laramie, Wyoming $\left(41^{\circ} \mathrm{N}\right)$, using balloonborne instruments, J. Geophys. Res., 108, 4167 , doi:10.1029/2002JD002514, 2003.

Dreiling, V. and Jaenicke, R.: Aircraft measurement with condensation nuclei counter and optical counter, J. Aerosol Sci., 19, 10451050, 1988.

Fahey, D. W., Keim, E. R., Boering, K. A., Brock, C. A., Wilson, J. C., Jonsson, H. H., Anthony, S., Hanisco, T. F., Wennberg, P. O., Miake-Lye, R. C., Salawitch, R. J., Louisnard, N., Woodbridge, E. L., Gao, R. S., Donnelly, S. G., Wamsley, R. C., Del Negro, L. A., Solomon, S., Daube, B. C., Wofsy, S. C., Webster, C. R., May, R. D., Kelly, K. K., Loewenstein, M., Podolske, J. R., and Chan, K. R.: Emission Measurements of the Concorde Supersonic Aircraft in the Lower Stratosphere, Science, 270, 5233, doi:10.1126/science.270.5233.70, 1995a. 
Fahey, D. W., Keim, E. R., Woodbridge, E. L., Gao, R. S., Boering, K. A., Daube, B. C., Wofsy, S. C., Lohmann, R. P., Hintsa, E. J., Dessler, A. E., Webster, C. R., May, R. D., Brock, C. A., Wilson, J. C., Miake-Lye, R. C., Brown, R. C., Rodriguez, J. M., Loewenstein, M., Proffitt, M. H., Stimpfle, R. M., Bowen, S. W., and Chan, K. R.: In situ observations in aircraft exhaust plumes in the lower stratosphere at midlatitudes, J. Geophys. Res., 100(D2), 3065-3074, 1995b.

Hamill, P., Jensen, E. J., Russel, P. B., and Bauman, J. J.: The life cycle of stratospheric aerosol particles, B. Am. Meteorol. Soc., 78, 1395-1410, 1997.

Hangal, S. and Willeke, K.: Overall efficiency of turbular inlets sampling at 0-90 degrees from horizontal aerosol flows, Atmos. Environ., 24A, 2379-2386, 1990.

Hämeri, K., Augustin, J., Kulmala, M., Vesala, T., Mäkelä, J., Aalto, P., and Krissinel, E.: Evaluation of homogeneous droplet formation inside UCPC (TSI Model 3025), J. Aerosol Sci., 26, 10031008, 1995.

Heintzenberg, J. and Ogren, J. A.: On the operation of the TSI-3020 condensation nuclei counter at altitudes up to $10 \mathrm{~km}$, Atmos. Environ., 19, 1385-1387, 1985.

Hermann, M., Stratmann, F., Wilck, M., and Wiedensohler, A.: Sampling Characteristics of an Aircraft-Borne Aerosol Inlet System, J. Atmos. Ocean. Tech., 18, 7-19, 2001.

Hermann, M. and Wiedensohler, A.: Counting efficiency of condensation particle counters at low-pressure with illustrative data from the upper troposphere, J. Aerosol Sci., 32, 975-991, 2001.

Hermann, M., Adler, S., Caldow, R., Stratmann, F., and Wiedensohler, A.: Pressure-dependent efficiency of a condensation particle counter operated with FC-43 as working fluid, J. Aerosol Sci., 36(11), 1322-1337, 2005.

Hinds, W. C.: Aerosol technology - properties, behaviour, and measurement of airborne particles; 2. Edition, John Wiley \& Sons, Inc., New York, 1999.

Jaenicke, R.: Untersuchung von Geräten zur Messung der Größenverteilung großer Aerosolteilchen in anthropogen nicht beeinflußten Atmosphären, Dissertation at the Faculty of Natural Science, Johannes Gutenberg-University, Mainz, 1970.

Jaenicke, R.: The optical particle counter. Cross-sensitivity and coincidence, J. Aerosol Sci., 30, 95-111, 1972.

$\mathrm{Ku}, \mathrm{B}$. K. and Maynard, A. D.: Generation and investigation of airborne silver nanoparticles with specific size and morphology by homogeneous nucleation, coagulation and sintering, J. Aerosol Sci., 37, 452-470, 2006.

Kürten, A., Curtius, J., Nillius, B., and Borrmann, S.: Characterization of an automated, water-based expansion condensation nucleus counter for ultra-fine particles, Aersol Sci. Technol., 39(12), 1174-1183, 2005.

McMurry, P. H.: The history of condensation nucleus counters, Aerosol Sci. Technol., 33, 297-322, 2000.

Middlebrook, A. M., Thomson, D. S., and Murphy, D. M.: On the purity of laboratory-generated sulfuric acid droplets and ambient particles studied by laser mass spectrometry, Aerosol Sci. Technol., 27, 293-307, 1997.

Minikin, A., Petzold, A., Ström, J., Krejci, R., Seifert, M., Velthoven, P. V., Schlager, H., and Schumann, U.: Aircraft observation of upper tropospheric fine particle aerosol in the northern an southern hemisphere at midlatitudes, Geophys. Res. Lett., 30, 1503-1509, 2003.
Murphy, D. M. and Ravishankara, A. R.: Temperature averages and rates of stratospheric reactions, Geophys. Res. Lett., 21(23), 2471-2474, 1994.

Murphy, D. M. and Schein, M. E.: Wind tunnel tests of a shrouded aircraft inlet, Aerosol Sci. Technol., 28, 33-39, 1998.

Murphy, D. M., Thompson, D. S., and Mahoney, M. J.: In situ measurements of organics, meteoritic material, mercury, and other elements in aerosols at 5 to 19 kilometers, Science, 282, 16641669, 1998.

Murphy, D. M., Cziczo, D. J., Hudson, P. K., and Thompson, D. S.: Carbonaceous material in aerosol particles in the lower stratosphere and tropopause region, J. Geophys. Res., 112, D04203, doi:10.1029/2006JD007297, 2007.

Myasishchev Design Bureau: High-altitude M55 Geophysika aircraft, Handbook, 3. Edition, Myasishchev Design Bureau, Moskau, 2002.

Noone, K. J. and Hansson, H.-C.: Calibration of the TSI 3760 condensation nucleus counter for non-standard operating conditions, Aerosol Sci. Technol., 13, 478-485, 1990.

Peter, T.: Microphysics and heterogeneous chemistry of polar stratospheric clouds, Annu. Rev. Phys. Chem., 48, 785-822, 1997.

Prather, M. J. and Rodriguez, J. M.: Antarctic ozone: Meteoritic control of $\mathrm{HNO}_{3}$, Geophys. Res. Lett., 15, 1-4, 1988.

Raasch, J. and Umhauer, H.: Errors in the determination of particle size distributions caused by coincidence in optical particle counter, Part. Part. Syst. Char., 1, 53-58, 1984.

Rosen, J. M.: The boiling point of stratospheric aerosols, J. Appl. Meteorol., 10, 1044-1045, 1971.

Rosen, J. M., Pinnick, R. G., and Hall, R.: Recent Measurements of Condensation Nuclei in the Stratosphere, Proceedings 3rd Conference Climatic Impact, Assessment Program, DOT-TCS-OST74-15, Department of Tranportation, Washington, D.C., 1974.

Saros, M. T., Weber, R. J., Marti, J. J., and McMurry, P. H.: Ultrafine aerosol measurement using a condensation nucleus counter with pulse height analysis, Aerosol Sci. Technol., 25, 200-213, 1996.

Schlager, H., Konopka, P., Schulte, P., Schumann, U., Ziereis, H., Arnold, F., Klemm, M., Hagen, D. E., Whitefield, P. D., and Ovarlez, J.: In situ observations of air traffic emission signatures in the North Atlantic flight corridor, J. Geophys. Res., 102(D9), 10739-10750, 1997.

Schulte, P., Schlager, H., Ziereis, H., Schumann, U., Baughcum, S. L., and Deidewig, F.: $\mathrm{NO}_{\mathrm{x}}$ emission indices of subsonic longrange jet aircraft at cruise altitude: In situ measurements and predictions, J. Geophys. Res., 102(D17), 21431-21442, 1997.

Schumann, U., Schlager, H., Arnold, F., Baumann, R., Haschberger, P., and Klemm, O.: Dilution of aircraft exhaust plumes at cruise altitudes, Atmos. Environ., 32(18), 3097-3103, 1998.

Sinclair, D. and Hoopes, G. S.: A Continuous Flow Condensation Nucleus Counter, J. Aerosol Sci., 6, 1-7, 1975.

Spurny, K. R.: Atmospheric condensation nuclei. P. J. Coulier 1875 and J. Aitken 1880. (Historical Review), Aerosol Sci. Technol., 32, 243-248, 2000.

Stolzenburg, M. R. and McMurry, P. H.: An Ultrafine Aerosol Condensation Nucleus Counter, Aerosol. Sci. Technol., 14, 4-65, 1991.

Thomas, A., Borrmann, S., Kiemle, C., Cairo, F., Volk, M., Beuermann, J., Lepuchov, B., Santacesaria, V., Matthey, R., Radukov, 
V., Yushkov, V., MacKenzie, A. R., and Stefanutti, L.: In situ measurements of background aerosol and subvisible cirrus in the tropical tropopause region, J. Geophys. Res., 107, 4763, doi:10.1029/2001JD001385, 2002.

TSI Incorporated: Model 3760A/3762 Condensation Particle Counter - Instruction Manual, Revision D, TSI Incorporated, 2002.

Turco, R. P., Whitten, R. C., and Toon, O. B.: Stratospheric Aerosols: Observation and theory, Rev. Geophys. Space GE, 20, 233-279, 1982.

Twohey, C. H.: Model calculations and wind-tunnel testing of an isokinetic shroud for high-speed sampling, Aerosol Sci. Technol., 29, 261-280, 1998.

Voigt, C., Schreiner, J., Kohlmann, A., Zink, P., Mauersberger, K., Larsen, N., Deshler, T., Kröger, C., Rosen, J., Adriani, A., Cairo, F., Di Donfrancesco, G., Viterbini, M., Ovarlez, J., Ovarlez, H., David, C., and Dörnbrack, A.: Nitric Acid Trihydrate (NAT) in Polar Stratospheric Clouds, Science, 290, 1756-1758, 2000.

Voigt, C., Larsen, N., Deshler, T., Kröger, C., Schreiner, J., Mauersberger, K., Luo, B., Adriani, A., Cairo, F., Di Donfrancesco, G., Ovarlez, J., Ovarlez, H., Dörnbrack, A., Knudsen, B., and Rosen, J.: In situ mountain-wave polar stratospheric cloud measurements, J. Geophys. Res., 108, D15, doi:10.1029/2001JD001185, 2003.

Voigt, C., Schlager, H., Luo, B. P., Drnbrack, A., Roiger, A., Stock, P., Curtius, J., Vössing, H., Borrmann, S., Davies, S., Konopka, P., Schiller, C., Shur, G., and Peter, T.: Nitric Acid Trihydrate (NAT) formation at low NAT supersaturation in Polar Stratospheric Clouds (PSCs), Atmos. Chem. Phys., 5, 1371-1380, 2005, http://www.atmos-chem-phys.net/5/1371/2005/.

Voigt, C., Schlager, H., Ziereis, H., Kärcher, B., Luo, B. P., Schiller, C., Krämer, M., Popp, P. J., Irie, H., and Kondo, Y.: Nitric acid in cirrus clouds, Geophys. Res. Lett., 33, L05803, doi:10.1029/2005GL025159, 2006.
Walter, S.: Simulation der Umströmung eines TeilstromentnahmeEinlasssystems für Höhenforschungsflugzeuge, Diploma thesis at the Institute for Physics of the Atmosphere, Johannes Gutenberg-University, Mainz, 2004.

Weber, R. J., Clark, A. D., Litchy, M., Li, J., Kok, G., Schillawski, R. D., and McMurry, P. H.: Spurious aerosol measurements when sampling from aircraft in the vicinity of clouds, J. Geophys. Res., 103, 28337-28346, 1998.

Wennberg, P. O., Cohen, R. C. Stimpfle, R. M., Koplow, J. P., Anderson, J. G., Salawitch, R. J., Fahey, D. W., Woodbridge, E. L., Keim, E. R., Gao, R. S., Webster, C. R., May, R. D., Toohey, D. W., Avallone, L. M., Proffitt, M. H., Loewenstein, M., Podolske, J. R., Chan, K. R., and Wofsy, S. C.: Removal of Stratospheric $\mathrm{O}_{3}$ by Radicals: In Situ Measurements of $\mathrm{OH}, \mathrm{HO}_{2}, \mathrm{NO}, \mathrm{NO}_{2}$, ClO, and BrO, Science, 266, 398-404, 1994.

Wilson, J. C., Blackshear, E. D., and Hyun, J. H.: An improved continuous flow condensation nucleus counter for use in the stratosphere., J. Aerosol Sci., 14, 387-391, 1983a.

Wilson, J. C., Hyun, J. H., and Blackshear, E. D.: The function and response of an improved stratospheric condensation nucleus counter, J. Geophys. Res., 88, 6781-6785, 1983 b.

Wilson, J. C., Stolzenburg, M. R., Clark, W. E., Loewenstein, M., Ferry, G. V., Chan, K. R., and Kelly, K. K.: Stratospheric sulfate aerosol in and near the northern hemisphere polar vortex: The morphology of the sulfate layer, multimodal size distribution, and the effect of denitrification, J. Geophys. Res., 97, 79978013, 1992.

Zhang, Z. Q. and Liu, B. Y. H.: Dependence of the performance of TSI 3020 condensation nucleus counter on pressure, flow rate and temperature, Aerosol Sci. Technol., 13, 493-504, 1990.

Zhang, Z. Q. and Liu, B. Y. H.: Performance of TSI 3760 Condensation Nuclei Counter at reduced pressure and flow rates, Aerosol Sci. Technol., 15, 228-238, 1991. 